\title{
Force Equalisation in Torque-Summed Electromechanical Actuators
}

By:

Name: $\quad$ Dr Fawaz Yahya Annaz (Associate Professor)

Address: $\quad$ Birmingham City University,

The School of Engineering and the Built Environment

Millennium Point, Curzon Street,

Birmingham B4 7XG

Phone number: $\quad+44(0) 1213004174$

Email: $\quad$ fawaz.annaz@bcu.ac.uk and fawazannaz@gmail.com

\section{Corresponding author information:}

Name: $\quad$ Dr Fawaz Yahya Annaz (Associate Professor)

Address: $\quad$ Birmingham City University,

The School of Engineering and the Built Environment

Millennium Point, Curzon Street,

Birmingham B4 7XG

Phone number: +44(0) 1213004174

Email: $\quad$ fawaz.annaz@bcu.ac.uk and fawazannaz@gmail.com 


\section{Abstract}

This paper examines the effects of force equalisation in a four lanes torque-summed architecture that was designed to drive a control surface similar to that on the Sea Harrier, following two motor failures. PID control was implemented to control the common output shaft. Force equalization was assessed in the presence of inherent internal motors parameters deviations as well as inherent drift in feedback transducers. 3-phase motor models were utilised to cater for the torque ripple effects. Force equalization was proven to be most effective on deviations due to drift in potentiometer readings.

Keyword: Force Fight; Force Equalization; Torque-Summed Architecture; Uncertainty Quantification, Sensitivity Analysis

Funding: This research did not receive any specific grant from funding agencies in the public, commercial, or not-for-profit sectors.

Conflict of interest: none declared 


\section{LIST OF SYMBOLS:}

\section{$A, B, C, D, E$ and $F \quad$ Constants}

\begin{tabular}{|c|c|}
\hline$B_{E_{n}}$ & Back emf \\
\hline$C_{H}$ & Hinge moment coefficient \\
\hline$\overline{\overline{\boldsymbol{c}}}_{\boldsymbol{f}}$ & Aileron chord \\
\hline $\mathrm{D}$ & Viscous damping coefficient \\
\hline$I_{n}$ & Phase current \\
\hline$I_{p}$ & Mutual phase current \\
\hline$I_{F p q}$ & Measured current in lane phase $_{q}$ \\
\hline$J_{a}$ & Control surface inertia \\
\hline$J_{m}$ & Motor moment of inertia \\
\hline$J_{r}$ & Resultant torque \\
\hline$J_{s}$ & Steady aerodynamic load component \\
\hline$J_{v}$ & Variable aerodynamic load component \\
\hline $\boldsymbol{K}_{E}$ or $\boldsymbol{K}_{e_{N}}$ & Voltage constant \\
\hline$K_{T}$ or $\boldsymbol{K}_{t_{N}}$ & Motor torque constant \\
\hline$L$ or $L_{N}$ & Phase winding inductance \\
\hline$L_{a}$ & Distance from hinge to aileron centre of gravity \\
\hline$m$ & Mutual inductance \\
\hline$M$ & Mach number $0.2 \leq \mathrm{M} \leq 1.0$ \\
\hline$M_{a}$ & Aileron mass \\
\hline$n_{g}$ & Maximum allowable aircraft manoeuvre \\
\hline$N$ & Number of pole pairs \\
\hline$n$ & Number of phases \\
\hline Pot $_{n}$ & Potentiometer reading on motor " $\mathrm{n}$ " \\
\hline $\bar{Q}(M)=0.5 \rho v^{2}$ & Dynamic pressure \\
\hline $\boldsymbol{R}$ or $\boldsymbol{R}_{N}$ & Phase winding resistance \\
\hline$S_{f}$ & Control surface span \\
\hline$T, T_{\text {Total }}$ & Total developed torque \\
\hline $\operatorname{Tach}_{n}$ & Tachometer reading on motor " $n$ " \\
\hline$T_{L}$ & Load friction torque \\
\hline$T_{o}$ & Output torque \\
\hline$T_{n}, T_{o_{n}}, T_{p h_{N}}$ or $t_{q_{n}}$ & Torque due to lane $\mathrm{n}$ \\
\hline$T_{p q}$ & Output torque due to lane phase $_{q}$ \\
\hline
\end{tabular}




\begin{tabular}{|c|c|}
\hline$T_{p}$ & Output torque due to lane $e_{p}$ \\
\hline $\boldsymbol{v}$ & Aircraft speed \\
\hline $\boldsymbol{V}_{\boldsymbol{n}}$ or $\boldsymbol{V}_{\boldsymbol{s}}$ & Terminal voltage \\
\hline$V_{i n_{n}}$ & Input voltage to a lane \\
\hline$\alpha$ & Angle of incidence \\
\hline$\alpha_{G}$ & Angle of incidence with respect to $\mathrm{M}$ \\
\hline$\delta_{a_{R e f}}$ & Aileron deflection reference input \\
\hline$\delta_{a}$ & Aileron deflection \\
\hline$\delta_{a}= \pm\left. 18^{\circ}\right|_{M=0.2}$ & Aileron deflection at $\pm \mathbf{1 8}^{\mathbf{o}}$ during low aircraft speed \\
\hline$\delta_{a}= \pm\left. 2^{o}\right|_{M=1}$ & Aileron deflection at $\pm \mathbf{1}^{\circ}$ during high aircraft speed \\
\hline$\delta_{\mathrm{a}}= \pm\left. 18^{\mathrm{o}}\right|_{\mathrm{M}=0.2,8 \mathrm{~Hz}}$ & $\pm 18^{\circ}$ Aileron deflected at $8 \mathrm{~Hz}$ frequency during low aircraft speed \\
\hline$\rho$ & Air density \\
\hline$N$ & Aircraft speed \\
\hline $\boldsymbol{\omega}=\dot{\boldsymbol{\theta}}$ & Angular velocity \\
\hline$\zeta$ & Damping coefficient \\
\hline $\boldsymbol{\theta}$ & Motor shaft mechanical angular displacement \\
\hline $\boldsymbol{\theta}_{e}$ & Shaft electrical angle $\equiv$ Lane electrical commutation angle \\
\hline
\end{tabular}




\section{INTRODUCTION:}

The purpose of the all-electric aircraft concept is the consolidation of all secondary power systems into electric power, which became feasible following the development of new electric motors and compact high-speed electronic circuits. The concept encouraged several studies that led to the development of the electromechanical actuator systems, survivability, vulnerability and fault tolerance test program, which addressed the benefits of the concept for the next generation fighters $[1,2,3]$.

This initiated several research programs including that by the avionics group in Queen Mary University of London [4], where the group investigated several smart electromechanical actuator designs, including the architecture shown in Fig. 1. The figure shows a four-lanes architecture, where individual lanes drive a common output shaft via a torque-summed gearbox assembly. The actuator was designed to meet the fail-operational/fail-safe requirement, which is usually accepted for flight critical applications [5], and to ensure the total isolation of failed motors, clutches were included to mechanically disconnect faulty lanes.

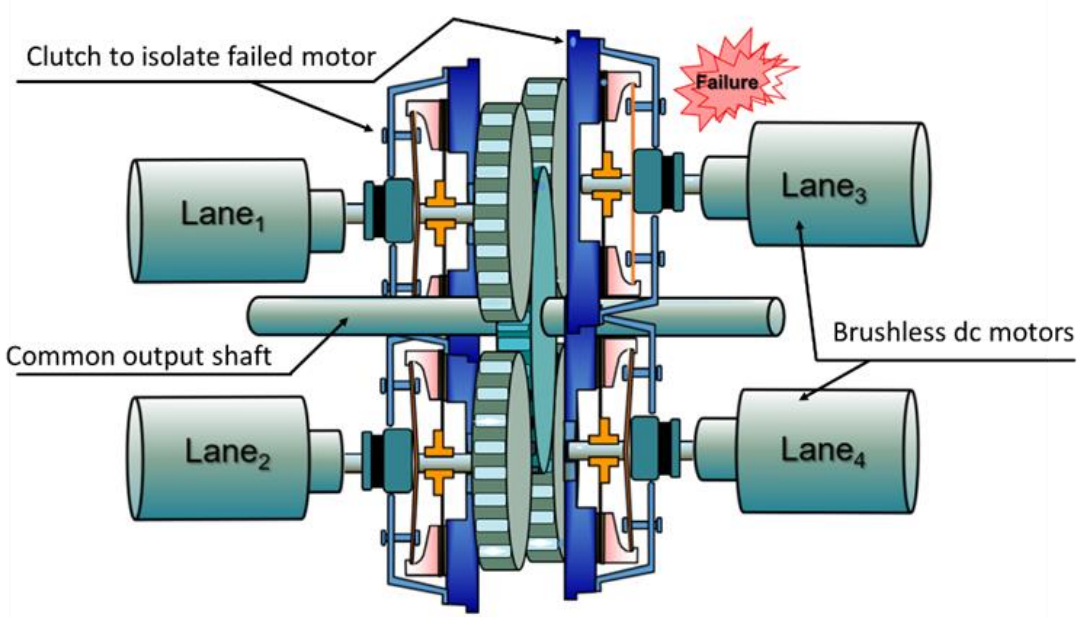

Fig. 1: Torque summed architecture of a four-lanes electromechanical actuator

The goal of this paper is to analytically investigate the possibility of force fight in such architectures; examine the effectiveness of implementing force equalisation in reducing or 
eliminating the force fight between the inherently mismatched lanes; and to identify and quantify contributions due to inherent disparities in both motor parameters and feedback transducers.

Over the years, several researchers have addressed various designs of hydraulic and electromechanical actuators. Some of the main contributors were Lockheed-Georgia and Sundstrand Corporation. Teamed with the USAF Flight Dynamics Laboratory, they developed a dual-motor device that drives a single ball-screw through a torque-summing gearbox electromechanical actuator. Initiated in 1982 the developments were described in several reports describing the hardware architecture of the actuator, demonstrating its capabilities in flight and its impact on the system flight control $[6,7,8,9]$. The reports described an electromechanical actuator that controlled the left-hand aileron control surface on the C-141 aircraft, with further laboratory and flight tests that were summarized in [10]. Further design concepts and duty cycle (such as: ground, take off, and climb operations) tests were also presented by the authors in [11]. Further US, European, Indian and Russian programmes that considered various designs for various applications were reported in the literature $[12,13]$. Although the studies did not address force fighting, they are worth receiving the brief description next.

In 2000, the US Air Force, Navy and NASA jointly sponsored the Electrically Powered Actuation Design Program to develop a series of actuators on a primary flight control surface of a tactical aircraft. The program compared the actuator performance to its hydraulic equivalent on the other aileron [12]. The study in [14] gave an overview and test results of the autonomous steering guidance algorithm of the Joint Unmanned Combat Air System X-45A during taxiing, taking-off and landing, where the aircraft utilised 18 linear electromechanical 
actuators to move: The six-trailing edge elevons; The two yaw thrust vectoring nozzle; the nose wheel steering; and the landing gear.

The authors in [15] described the Large Electro Mechanical Actuation System (LEMAS) Program, which was jointly funded by Lucas Aerospace and the UK Department of Trade and Industry to investigate issues that are related to large electromechanical actuators. The program initially considered the use of a permanent magnet brushless dc motor, before finally selecting 4-phase switched reluctance motors [16]. The described actuator had a linear arm arrangement, with the motor driving a gearbox to operate a ball-screw mechanism to move the spoiler. Actuators that implemented direct drive permanent magnet synchronous motors were also described by the authors in [17]. Smiths Aerospace (Wolverhampton) demonstrated an actuator that delivered a force in excess of $159 \mathrm{kN}$ to drive an aircraft rudder.

The authors in [18] described an electromechanical actuation system that acted on the wing surfaces of a mid-sized commercial aircraft, with particular emphasis on flap systems. The authors further described in 2010 a dual-redundant electromechanical actuator that drove the electric landing gear's extend and retract system, which was capable of delivering torques in excess of $7,000 \mathrm{Nm}$ at speeds in excess of $18^{\circ} / \mathrm{sec}$ [19].

The authors in [20] presented an approach to optimise the weight of a helicopter primary flight control to a Helicopter Electromechanical Actuation Technology program. The Control Actuation Systems Group (Vikram Sarabhai Space Centre of the Indian Space Research Organisation) described the design of a quadruplex 3-phase brushless DC roller screw spurgeared linear actuator to move a gimbal control system, with a stall force of $96.7 \mathrm{kN}[21,22]$. The author in [23] described the development of power drives to a planetary roller-screw gear 
electromechanical actuator to improve the accuracy and reliability of special equipment used for the integration and installation of large-sized and large-mass products that are associated with a rocket carrier.

Technodinamika Holding which is part of the Rostec State Corporation conducted several research programs on the development of electromechanical actuators. Some of these included landing gear electrification to replace the current landing gear retraction and extension hydraulic drive system for the Tupolev Tu-204 aircraft [24]; and the thrust reverser actuator system for the Aviadvigatel PD-14 engine, which is the first system of its kind in Russia [25].

One very interesting and distinguished unique design was presented by Pond and Wyllie. The authors utilised electromagnetic torque-summing, generated by a quad redundant winding, where they attempted to increase system reliability by removing the gearbox assembly, which is the least reliable component in any electromechanical system [13]. Unfortunately, the authors reported persistent performance problems due to motor control circuits immaturity, circuit noise, and high current and voltage spikes, which caused frequent power transistors failures. This forced the developers to reduce the supply voltage and the current below the nominal design values, which (naturally) constrained the actuator overall performance.

Studies that addressed force fighting include the studies in $[26,27,28,29,30,31,32,33,4$, 34]. The authors in [26] described the electromechanical actuation systems in the X-38 project, which main drive was to perform multiple unmanned drop test vehicles for unmanned space flight Proto-Flight Vehicle 201 (V-201). The program examined the design and development of the vehicle's complex seven single-fault-tolerant-actuated subsystems that are capable of repeatedly deploying or storing the fins to allow for the orbiter payload bay doors to be closed. 
The authors in [27] describe the same X-38 project, but focused on the actuation systems that drove the lower rear flaps of the Crew Rescue V-201. The project, tested two flaps that were driven by eight controllers and six motors. Each surface actuation subsystem has four controllers to control the housed three motors in the subsystem unit. All the controllers run online simultaneously, communicating with each of the three motors that powered each of the electromechanical actuators that drove the flap. The controllers included motor synchronization-codes to prevent force fighting between the motors.

The Integrated Vehicle Health Management (IVHM) Technology experiment for the unpiloted X-37 vehicle (which was planned to orbit the earth for up to 21 days before landing) was described in [28]. The objectives of the experiment were to perform real-time fault detection and isolation for the electrical power system and electro-mechanical actuators.

The authors in [29] described an Advanced Technology Demonstrator Test Vehicle of the allelectric actuated aircraft X-33, developed by Lockheed Martin. The X-33 has four identical onboard actuators that were used to move the two wings and the two rudders; and two actuators that were used to move the engine hood. All actuators used three-phase brushless motors that were capable of driving a 3,390 Nm loads. The hood actuators differed from the other four as they had longer wire bundles, oblique tail stocks and modified housing. The author in [30] identified the required tests that will adequately characterize and model the on-board electromechanical actuators, using gained knowledge from the Hypersonic X-43A Project.

The author in [31] explored the force fight between the two X-38 electromechanical actuators (which was also mentioned in [26]) in a passive spring-loaded dual testbed. The authors 
developed and validated the model against flight test data, and finally reproduced modelproduced data onto the rig. The authors reported successful reproduction of load profiles for multiple manoeuvres for at least one type of aerospace application, and recommended further future tests. The author in [32] proposed force equalization control strategies to a hybrid system of electrohydraulic and electromechanical actuators that drove a single aileron control surface. The authors pre-validated two strategies (integrating a force fighting signal to compensate the position control, and operating in master/slave modes) on initially a virtual testbench and then experimentally. However, the study did not consider power sources consolidation and utilised both hydraulic and electric power sources; and considered a parallel summing arrangement of the electrohydraulic and the electromechanical actuators.

The 4-lanes architecture that was developed by the Queen Mary University of London Group was designed to move the inner board aileron on the Sea-Harrier. The actuator matched its hydraulic counterparts in operation, redundancy and safety $[4,33,34]$. The group made a significant contribution by considering different architectures with various levels of modelling complexity and have investigated different threshold setting methods and different crossmonitoring techniques. This paper adds to these contributions and (as mentioned above) aims to understand force equalisation, its effectiveness and limitations in reducing or eliminating force fight in architectures with inherent (motor and feedback transducers) disparities.

\section{System Under Consideration:}

The study presented here is based on a 4-lanes actuation system that is capable of overcoming the aerodynamic and inertial loads on a control surface that is similar to the inner-board aileron on the Sea Harrier aircraft. The study assumes repeated redundancy in the driving channels and feedback transducers, with each lane containing a brushless motor and a dedicated 
microprocessor/s to perform various control and monitoring actions. The actuator was designed to maintain its performance following a maximum of two failures.

Fig. 2 shows a single-type torque-summed architecture, with the resultant driving torque equals to the algebraic sum of the individual lane torques. This explains concerns over the possibility of force fight between the active lanes. Repeatability in hardware does not mean that the hardware (lanes or feedback transducers) is fully matched, as it is practically difficult to produce $100 \%$ fully matched parts. The paper will investigate and present the effectiveness of implementing force equalization to minimise the impact of any inherent mismatching in lanes parameters and drift in transducers readings.

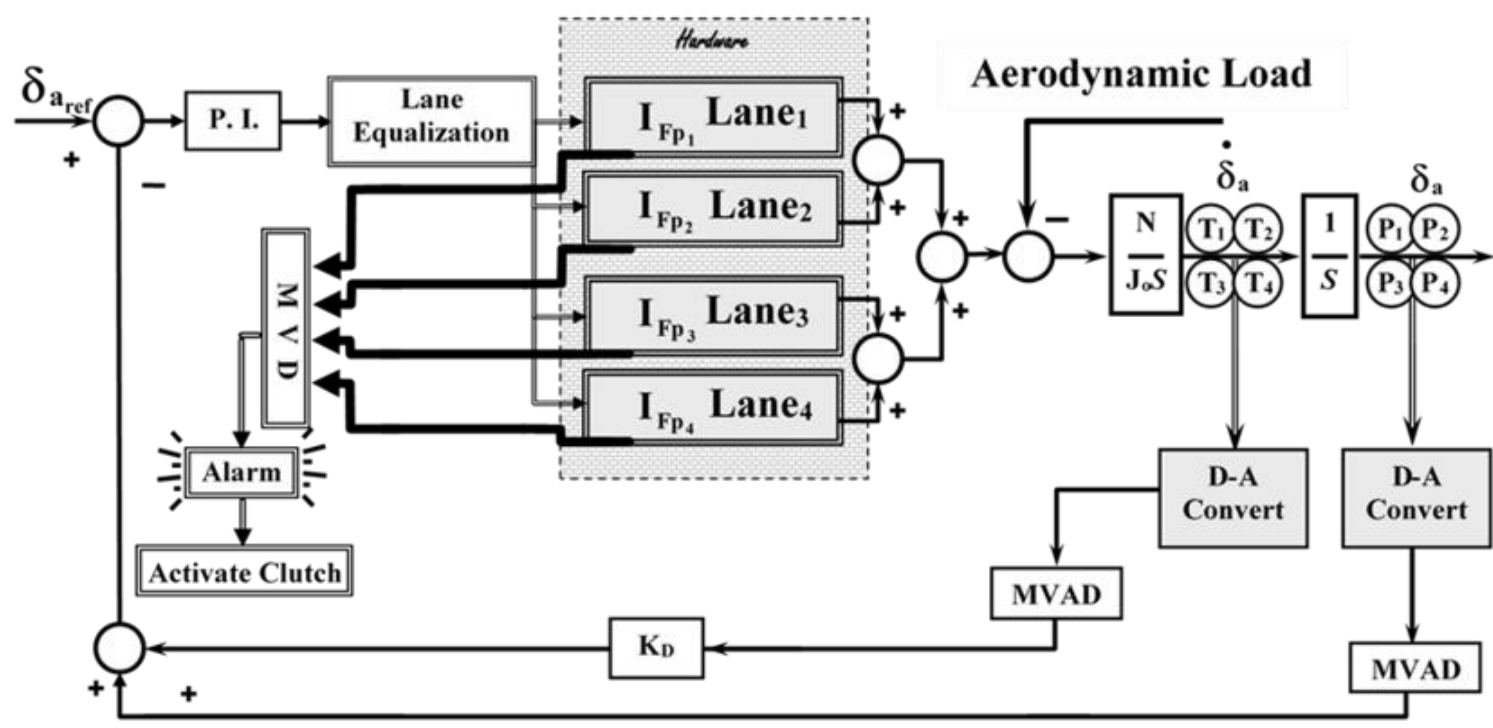

Fig. 2: Closed loop block diagram of a torque summed architecture

In this architecture an isolated faulty lane (or lanes) will appear as inertial loads to the other operational lanes, therefore, it is vital to include clutches to ensure isolation of the faulty lanes. As all the individual lanes and the final common output shaft are locked together, it is irrelevant where the feedback sensors are placed. The use of motors' built-in tachometers could result in a loss in a reading following the isolation of a failed lane, however, better readings are produced 
if the built-in tachometers are used because of the higher shaft speeds. Failures in any of the feedback transducers will result in its isolation, thus, modifying the feedback signal reading to the average value of the remaining active sensors. Regardless of the failures type, isolations will result in failure transients that will impact the aircraft response. Therefore, designs have to conform to good practices in various military standard specifications to meet the actuators and aircrafts specification guidelines in Table $1[35,36]$.

\section{Mathematical Modelling:}

The actuator mathematical model includes: models for the four lanes of actuation, the load model, the gearbox and drive electronics. The load model, includes both inertial and aerodynamic loads. To fully assess the possibility of any force fight between lanes, 3-phase motor models were developed (along with their electronic drives) to cater for the torque ripple effect contributed by the individual motors. Random parameters deviations were also taken into account to cater for any inherent lane disparities that might affect the magnitude of the resulting torque ripples (and of course the set threshold values, which is not in the realm of this paper). Initially the work was developed on the Advanced Continuous Simulation Language [37] and was recently redeveloped on the MATLAB-Simulink environment, therefore, the following discussions will also include detailed Simulink models.

Table 1: Actuators and aircrafts design specification guidelines

\footnotetext{
- Maximum rotary output of $\pm 18^{\circ}$

क् $\bigcirc$ Minimum output rate of $30 \mathrm{deg} / \mathrm{sec} \approx 0.5 \mathrm{rad} / \mathrm{sec}$

- $8 \mathrm{~Hz}$ bandwidth at $1^{\circ}$ based on $3 \mathrm{~dB}$ at $5 \%$ of maximum output amplitude

- Control surface similar to that of a Sea - Harrier $18^{\circ}$

o Probability first nuisance disconnect $<10^{-4}$.

- Sea level aircraft speed range of $0.2 \geq M \geq 1.0$

$\mp \quad \circ$ Maximum aileron authority limit of $18^{\circ}$ and $2^{\circ}$ at low and high aircraft speeds

$\circ \quad \delta_{\mathrm{aMAL} @ 0.2}=18^{\circ} \& \delta_{\mathrm{aAL} @ 1.0}=2^{\circ}$, with linear intermediate speed variation

○ Maximum aircraft manoeuvre $-1.0 \sim 5.0 \mathrm{~g}$

- Maximum bank - angle to first failure transient $=3^{\circ}$.

- Maximum roll - rate to first failure transient $=3^{\circ} / \mathrm{sec}$.
} 


\subsection{BRUSHLESS DC Motor Modelling}

The basic structure and operation of classical dc machines were given in [33, 4], where the author developed lumped models for the brushless dc motors. In the 3-phase model, these lumped models represent the models for each of the single phases, and will take into account the effect of phase shifting and the mutual inductance [34]. The actuator electrical and mechanical equations are summarised in equations (1 3), below:

$$
\begin{aligned}
& V_{n}=R I_{n}+L \dot{I}_{n}+m \frac{d}{d x} \sum_{p \neq n}^{3} I_{p}+\dot{\theta} K_{E} \sin \left\{N \theta-120^{\circ}(n-1)\right\} \\
& T=\sum_{n}^{3} K_{T} I_{n} \sin \left\{N \theta-120^{\circ}(n-1)\right\} \\
& \dot{\omega}=\frac{T_{o}}{J_{m}+J_{a}}
\end{aligned}
$$

Based on a 3-phase model, the electrical equation maybe rewritten (equations 4 12) to express the discrete terminal states.

$$
\begin{aligned}
& \dot{I}_{1}=\frac{1}{L}\left[F_{1}-2 m\left(\frac{F_{4}-F_{5}}{2 m+L}\right)-m\left(\frac{F_{2}-F_{3}}{m-L}\right)\right] \\
& \dot{I}_{2}=\frac{F_{4}-F_{5}}{2 m+L} \\
& \dot{I}_{3}=\frac{F_{2}-F_{3}}{m-L}+\frac{F_{4}-F_{5}}{2 m+L}
\end{aligned}
$$

Where:

$$
\begin{aligned}
& F_{1}=V_{1}-R I_{1}-B E_{1} \\
& F_{2}=V_{2}-R I_{2}-B E_{2} \\
& F_{3}=V_{3}-R I_{3}-B E_{3} ; \\
& F_{4}=\left(m F_{1}-L \cdot F_{2}\right) /(m-L) \\
& F_{5}=m\left(F_{2}-F_{3}\right) /(m-L)
\end{aligned}
$$

Where $B E_{n}$ represents the generated back EMF in the phase, and is represented by the $4^{\text {th }}$ term in Equation (1) and is listed again in Equation (12):

$$
B E_{n}=\dot{\theta} K_{E} \sin \left\{N \theta-120^{\circ}(n-1)\right\}
$$


In this architecture, the total generated output torque $\left(T_{O}\right)$ is the algebraic sum of the individual lanes $T_{O_{1}}, T_{O_{2}}, T_{O_{3}}$ and $T_{O_{4}}$, as shown in Equation (13). The torque generated in any of the lanes is the sum of the individual synchronously triggered phase torques. Table 2 describes commutation electrical angles that yields useful torques of $\left(\sqrt{3} K_{T} V_{S} / R\right) \angle \theta^{o}$ by the individual phases, where $V_{S}$ being the phase voltage.

$$
T_{O}=T_{O_{1}}+T_{O_{2}}+T_{O_{3}}+T_{O_{4}}
$$

Fig. 3 shows the Simulink block diagram of a 3-phase single lane, the basic lumped model to one of the phases, and the switching circuit that commutates each phase by accurately distributing the input voltages $V_{i n 1}$ to the relavant voltage nodes $V_{1}, V_{2}$ and $V_{3}$ depending on the shaft electrical angle $T$ heta ${ }_{1}$.

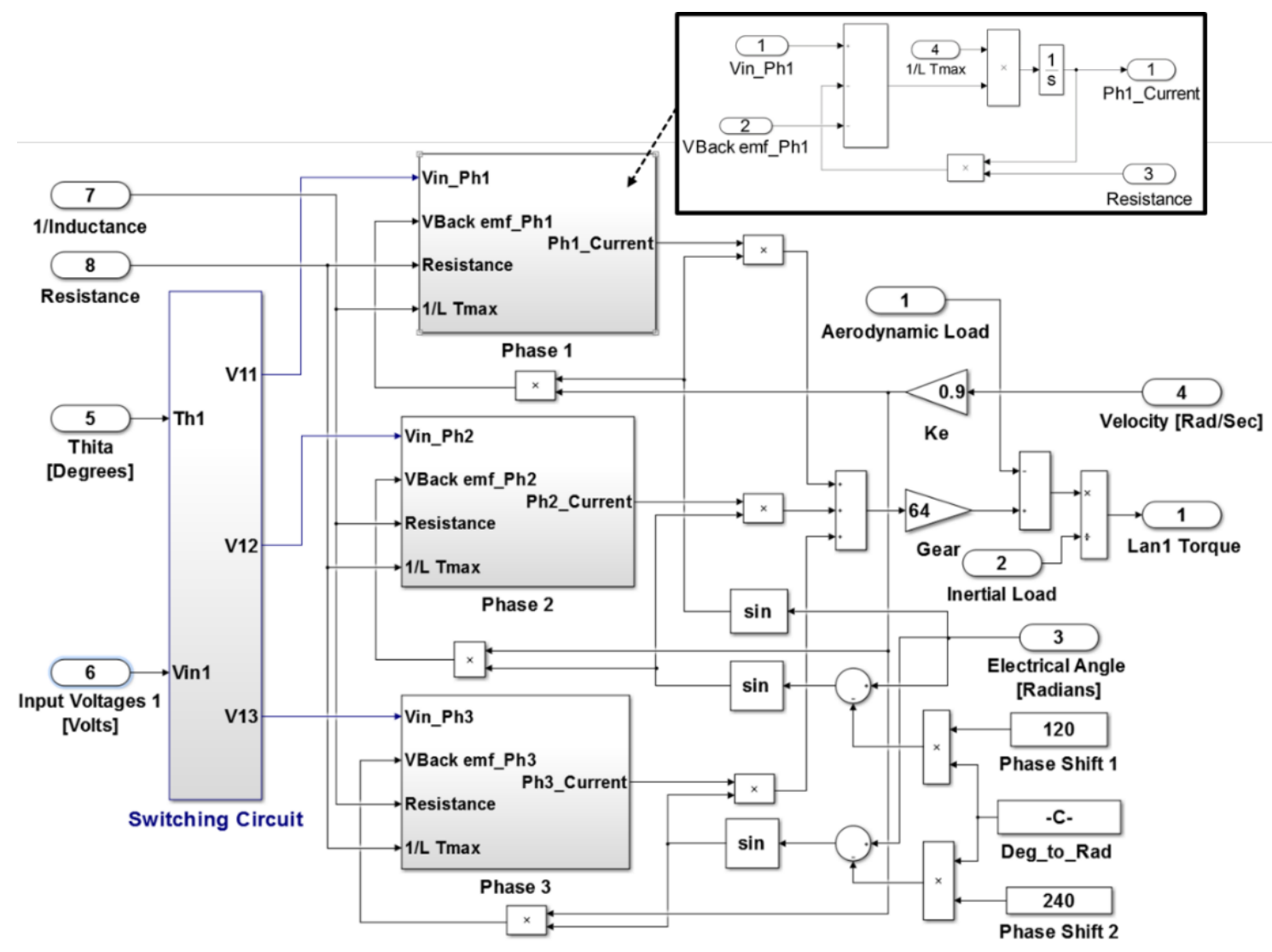

Fig. 3: The 3-phase BDM Simulink model

Fig. 4 shows the four subsystems that are associated with the switching circuit: Fig. 4a shows the top sub layer of the switching circuit; Fig. $4 \mathrm{~b}$ shows the commutation angle normalising 
block (to ensure reading shaft electric angles between $0 \sim 360^{\circ}$ ); Fig. $4 \mathrm{c}$ shows the necessary logic that ensures accurate commutation within a specific electrical angle range; and Fig. 4d makes the appropriate node setting according to the commutation angle.

The 3-phase model for one of the lanes was verified in Simulink. Fig. 5a shows the transient phase and total output torques versus the electrical switching angles, which are in agreement with the results shown in Table 2. Fig. 5b shows the no-load speed and the no-load torque versus time. In both figures the inherent torque ripple is clearly evident.

If all the four lanes were perfectly matched, then the torque contribution by the other lanes ( $T_{2} \sim T_{4}$ ) should be superimposed on $T_{1}$, eliminating the force fight possibility. However, if the parameters were mismatched, force fight would be possible. To have a complete assessment, the aerodynamic model was also simulated and is discussed in the next section.

Table 2: Commutations to generate useful torques

$\begin{array}{cc}\text { Generated Torque in: } & \text { Electrical angles where useful phase torque is genera } \\ \text { Phase }_{1} & 30^{\circ} \leq \theta_{e} \leq 150^{\circ} \text { and } 210^{\circ} \leq \theta_{e} \leq 330^{\circ} \\ \text { Phase }_{2} & 330^{\circ} \leq \theta_{e} \leq 90^{\circ} \text { and } 150^{\circ} \leq \theta_{e} \leq 270^{\circ} \\ \text { Phase }_{3} & 270^{\circ} \leq \theta_{e} \leq 30^{\circ} \text { and } 90^{\circ} \leq \theta_{e} \leq 210^{\circ}\end{array}$

\subsection{THE LOAD MODEL:}

To accurately assess and evaluate the actuator performance, a load model was developed to cater for the inertial and the aerodynamic loads. The actuator was assumed to act on a surface similar to that of the inner-board aileron of the Sea Harrier. Therefore, assuming an aileron control surface with mass $M_{a}$ and a leverage distance (from the centre of gravity to leverage hinge) $L_{a}$, the aileron moment of inertia is given by the expression in equation (14). 


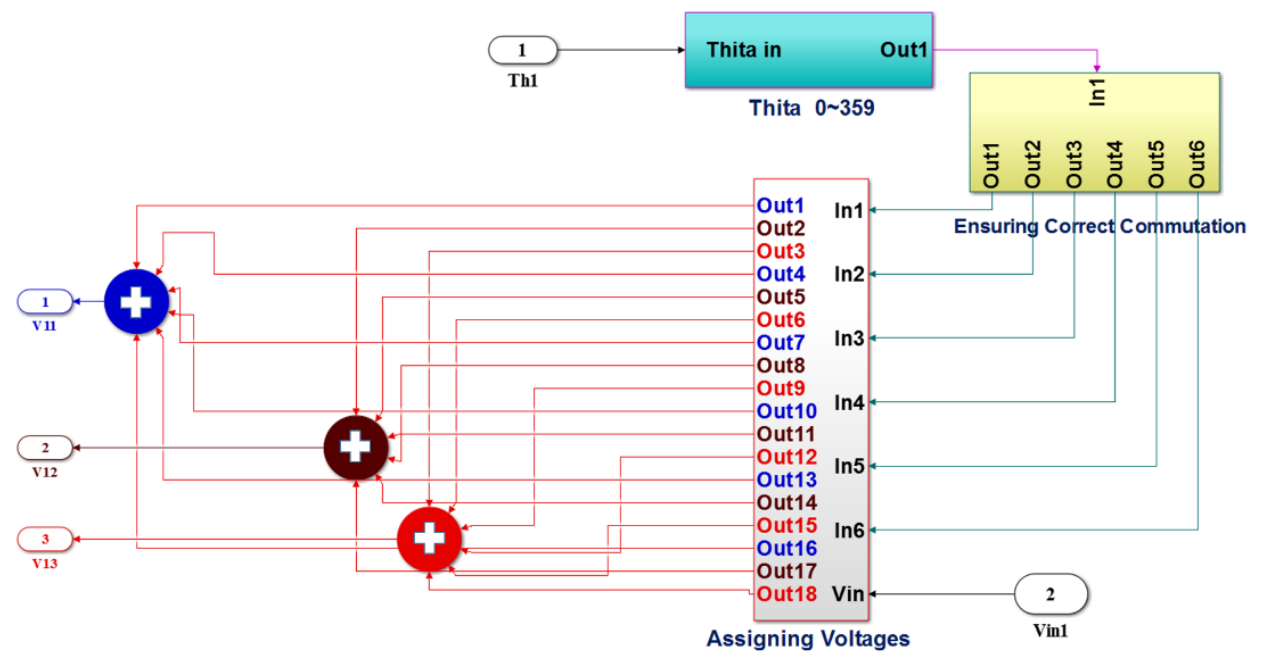

a) Top layer of the switching circuit subsystem

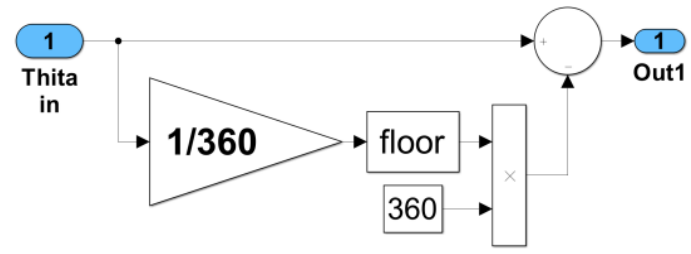

b) Normalising Thita 0 359

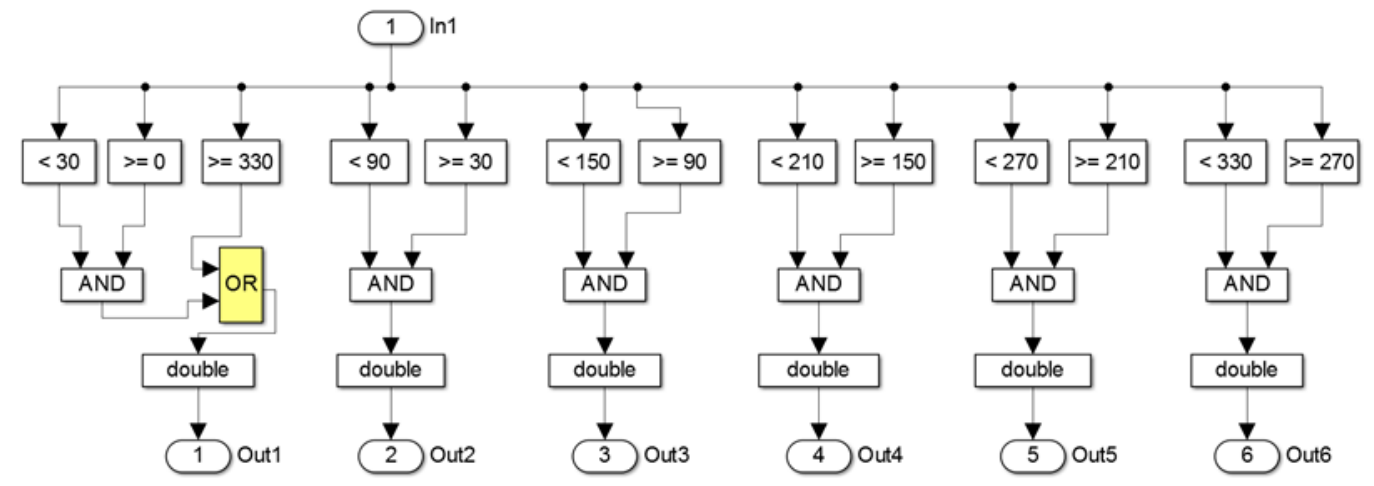

c) Subsystem that ensures correct commutation

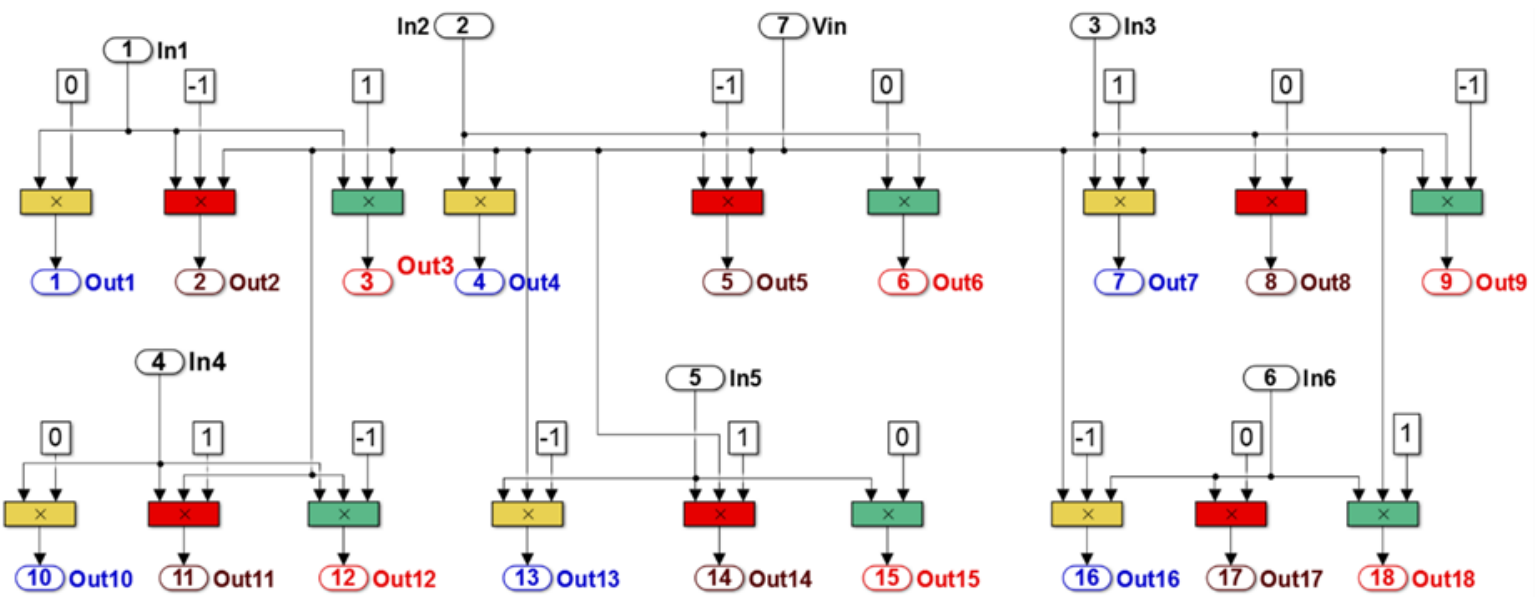

d) Subsystem that ensures correct node voltage allocation

Fig. 4: Simulink 3-phase BDM motor switching circuit and other associated subsystems 


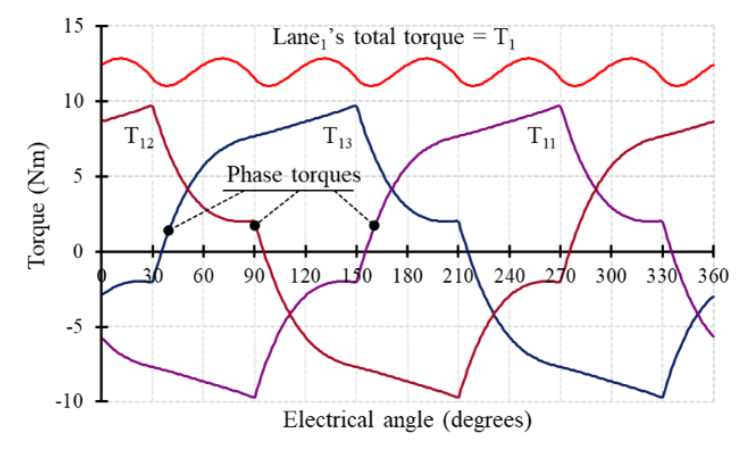

(a)

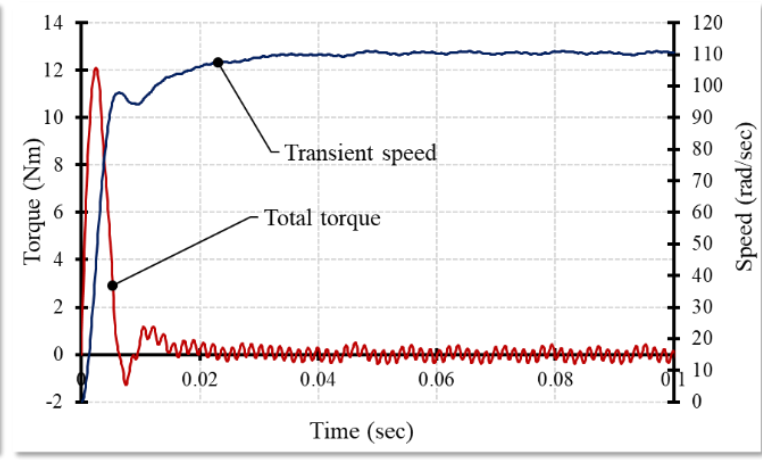

(b)

Fig. 5: The transient response of a single lane

The aerodynamic load model was derived to cater for maximum aircraft speeds manoeuvres $(0.2 \leq M \leq 1.0)$. Full treatment of the model derivation maybe found in [34], however, here only key equations are listed in (15) (22). The terms $\overline{\bar{c}}_{f}$ and $S_{f}$ are constants that depend on the aileron geometry. Moreover, the polynomial in (16) is used to approximately calculate the dynamic pressure, $0.5 \rho v^{2}$.

$$
\begin{aligned}
& J_{a}=M_{a} L_{a}{ }^{2} \quad K g \cdot m^{2} \\
& H=\left(0.5 \rho v^{2}\right)\left(\overline{\bar{c}}_{f}\right)^{2}\left(S_{f}\right)\left(C_{H}\right) \\
& \bar{Q}(M)=A M^{5}+B M^{4}+C M^{3}+D M^{2}+E M+F \\
& C_{H}=0.55 \alpha_{G}+\frac{0.9}{57} \delta_{a} \\
& H=[\overbrace{0.151791 \alpha_{G}}^{\begin{array}{c}
\text { Steady } \\
\text { Component }
\end{array}}+\overbrace{4.3574 \times 10^{-3} \delta_{a}}^{\begin{array}{c}
\text { Variable } \\
\text { Component }
\end{array}} \bar{Q}(M)=H_{\text {Steady }}+H_{\text {Variable }} \\
& n_{g}=4.4 M-0.4 \\
& \alpha=1286.524 / \bar{Q}(M) \text { [in radians] } \\
& \delta_{a}=-20 M+22 \quad \text { [in degrees] }
\end{aligned}
$$


The model reveals that the acting loads consist of two components, an inertial component due to sinusoidal excursions and an aerodynamic load, which is made up of a varying component that is due to the aileron deflection $\left(\delta_{a}\right)$, and a constant component that is proportional to the wing angle of incidence $\left(\alpha_{G}\right)$.

The inertial load is proportional to the size and the frequency of these sinusoidal excursions. In this study, the actuator was assumed to describe maximum excursions of $\pm 18^{\circ}$ at low aircraft speeds, and $\pm 2^{\circ}$ at high aircraft speed, at maximum frequency of $8 \mathrm{~Hz}$. Therefore, while the aerodynamic load depends on the aircraft speed and is independent of the aileron frequency movement, the inertial load is affected by both, where it is expected to be maximum at the $\delta_{a}=$ $\pm\left. 18^{\circ}\right|_{M=0.2,8 \mathrm{~Hz}}$ flight condition.

Table 3 gives a summary of simulation tests over the flight envelope $(0.2 \leq M \leq 1.0)$ and aileron frequencies in the range $1 \sim 8 \mathrm{~Hz}$. The table reveals that the range of inertial loads was found to be $\left.10 \mathrm{Nm}\right|_{M=1} \leq J_{a} \leq\left. 5821 \mathrm{Nm}\right|_{M=0.2}$. The variable component of the aerodynamic load $\left(J_{v}\right)$ is aileron and aircraft speed dependent. The steady component $\left(J_{s}\right)$ is aircraft speed dependant and is always constant over the two aileron surfaces, regardless of the surface deflection, it will be acting with or against the inertial load depending on the aileron deflection direction. Therefore, in one direction $J_{s}$ assists $J_{a}$ opposing $J_{v}$; and in the other direction $J_{s}$ opposes $J_{a}$ and assists $J_{v}$. Typical aerodynamic components were found to be significantly smaller than the inertial loads and were in the range: $112 \mathrm{Nm} \leq J_{s} \leq 976 \mathrm{Nm}$ and $219 \mathrm{Nm} \leq$ $J_{v} \leq 1355 \mathrm{Nm}$. Thus, the typical expected resultant loads were found to be in the range: $240 \mathrm{Nm} \leq J_{r} \leq 5714 \mathrm{Nm}$. These figures are also highlighted in Table 3. Therefore, the actuator had to be designed to overcome the maximum resultant torque with two lanes failing. 
Table 3: Typical values of aerodynamic, inertial and resultant loads in Nm

\begin{tabular}{|c|c|c|c|c|c|c|c|c|c|c|}
\hline & & & & Aer & ynami & Load & & & & \\
\hline & & 0.2 & 0.3 & 0.4 & 0.5 & 0.6 & 0.7 & 0.8 & 0.9 & 1 \\
\hline & $J_{v}$ & 219 & 444 & 703 & 963 & 1187 & 1334 & 1355 & 1191 & 769 \\
\hline & $J_{s}$ & 112 & 254 & 460 & 547 & 633 & 719 & 805 & 890 & 976 \\
\hline & Freq. ( & & & & & & & & & \\
\hline & 1 & 91 & 81 & 17 & 61 & 51 & 40 & 30 & 20 & 10 \\
\hline 8 & 2 & 364 & 323 & 283 & 243 & 202 & 162 & 121 & 81 & 40 \\
\hline 0 & 3 & 819 & 728 & 637 & 546 & 455 & 364 & 273 & 182 & 91 \\
\hline శ్ & 4 & 1455 & 1294 & 1132 & 970 & 808 & 647 & 485 & 323 & 162 \\
\hline$\beth$ & 5 & 2274 & 2021 & 1769 & 1516 & 1263 & 1011 & 758 & 505 & 253 \\
\hline 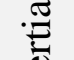 & 6 & 3274 & 2911 & 2547 & 2183 & 1819 & 1455 & 1091 & 728 & 364 \\
\hline$\stackrel{\Phi}{\Xi}$ & 7 & 4457 & 3962 & 3467 & 2971 & 2476 & 1981 & 1486 & 990 & 495 \\
\hline & 8 & 5821 & 5174 & 4527 & 3881 & 3234 & 2587 & 1940 & 1294 & 647 \\
\hline & 1 & 240 & 617 & 1146 & 1449 & 1769 & 2013 & 2130 & 2061 & 1735 \\
\hline 5 & 2 & 257 & 375 & 880 & 1267 & 1618 & 1891 & 2039 & 2000 & 1705 \\
\hline ర్తే & 3 & 712 & 538 & 526 & 964 & 1365 & 1689 & 1887 & 1899 & 1654 \\
\hline$\stackrel{\circ}{\lrcorner}$ & 4 & 1348 & 1104 & 889 & 554 & 1012 & 1406 & 1675 & 1758 & 1583 \\
\hline 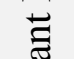 & 5 & 2167 & 1831 & 1526 & 1100 & 709 & 1042 & 1402 & 1576 & 1492 \\
\hline$\stackrel{\Xi}{\Xi}$ & 6 & 3167 & 2721 & 2304 & 1767 & 1265 & 840 & 1069 & 1353 & 1381 \\
\hline$\vec{\otimes}$ & 7 & 4350 & 3772 & 3224 & 2555 & 1922 & 1366 & 936 & 1091 & 1250 \\
\hline & 8 & 5714 & 4984 & 4284 & 3465 & 2680 & 1972 & 1390 & 993 & 1098 \\
\hline
\end{tabular}

\section{Control System:}

A Proportional and Integral (PI) action controller with Velocity feedback was employed to cater for any load nonlinearities. This modifies the open loop poles to pass through the dominant complex poles, thus maintaining relatively constant undamped natural frequency. Two approaches were adopted to examine the effect of force fight between mismatched lanes, in the presence and absence of force equalisation (FE).

Fig. 6a shows a system that utilises FE. In this system, the controller outputs a signal that simultaneously drives all the motors' nodes via a common state-dependent and sequentially activated transistors. The voltages on the nodes were assumed to linearly vary between \pm 100 
volts (if the controller outputs values were within the permitted range), however, if this range is exceeded, the transistors will be driven into saturation modes. In FE, the position and velocity feedback signals are the measured averages of positions and velocities of the four redundant potentiometers and tachometers (which are either placed on the common output shaft or on the individual motors). Fig. 6b shows a system that does not consider FE (No-FE). In this design, each of the lanes will contain its own dedicated PID controller, with feedback signals measured by the four potentiometers and tachometers on the common output shaft or from those on the individual lanes.

\section{INHERENT RANDOMNESS:}

In this study, the parameters $R, L, K_{T}$ and $K_{E}$ on the selected motors varied with the tolerances $\pm 12 \%, \pm 30 \%, \pm 10 \%$ and $\pm 10 \%$, respectively [38]. Feedback transducers (Rotary Variable Differential Transformers, RVDTs) were found to vary in tolerance depending on the operating range and the manufacturing brand. For example, the accuracy of RVDTs made by Kollmorgen, Kearfortt Corporation, and Moog Inc. ranged between $\pm 0.7 \sim 1.7 \%, \pm 2.3 \%$ and $\pm 1.4 \%$, respectively $[39,40]$.

In this research, the architecture was assumed to have feedback transducers with a minimum tolerance of $\pm 1 \%$, however, tests were also conducted with higher tolerances to verify the system performance. Practically, this indicates growth in undetected drift in transducers' readings. The two configurations of FE and No-FE were validated by comparing systems with nominal parameters against plants with parameters and tolerances that yield maximum torque disparities. Therefore, parameters and tolerances that yielded extreme torques had to be first identified. This was achieved by considering all the possible variation in motor parameters tolerances. The M-file shown in Fig. 7 (along with the Simulink Model in Fig. 3) was used to identify the two extreme Torques shown in equations (23) and (24). 


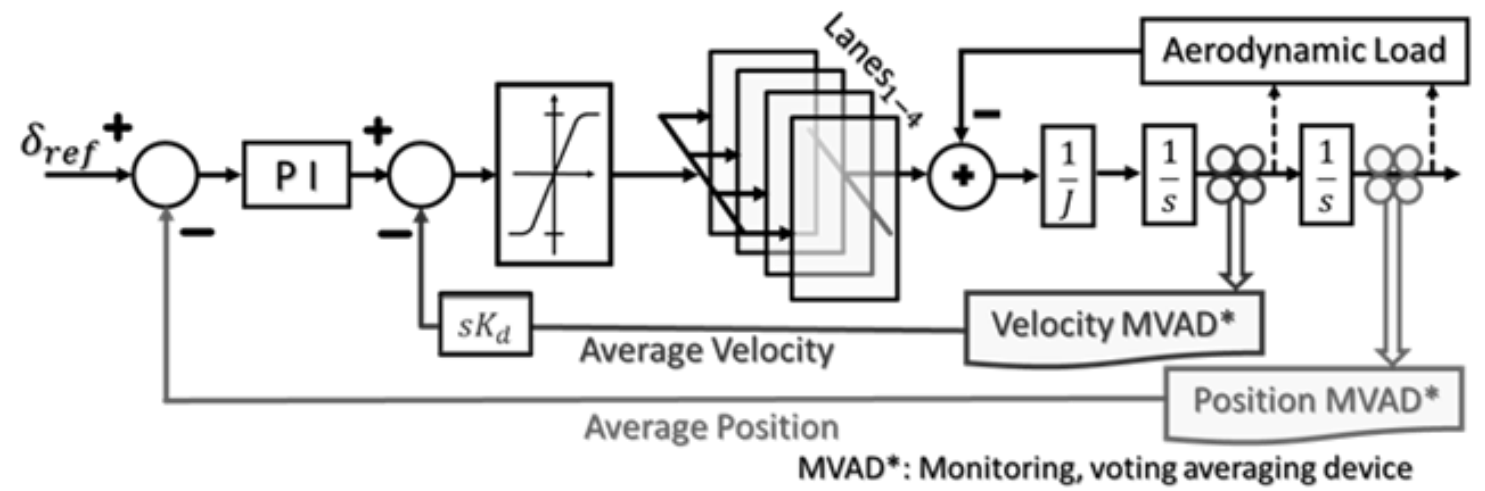

(a) Force equalization scheme

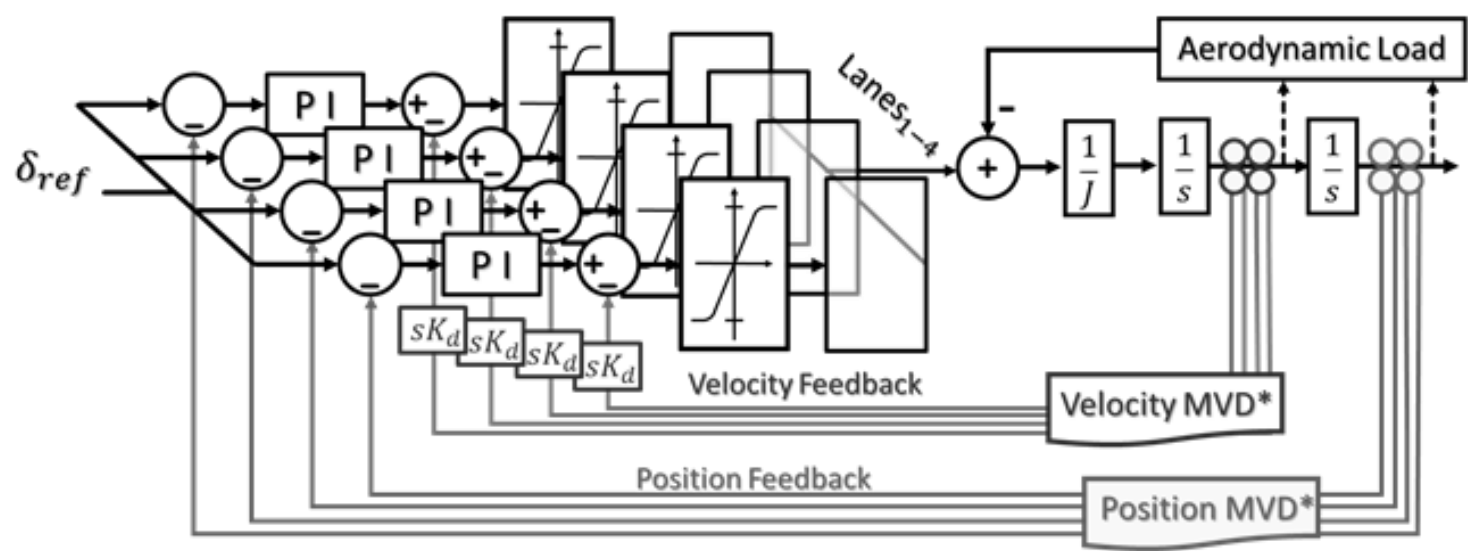

(b) No-force equalization scheme

Fig. 6: Closed loop block diagram of the torque summed architecture

$$
\begin{aligned}
& T_{\text {max }}=f\left(R_{\text {min }}, L_{\text {min }}, K_{T_{\text {max }}}, K_{E_{\text {min }}}\right) \approx 15.53 \mathrm{Nm} \\
& T_{\text {min }}=f\left(R_{\text {max }}, L_{\text {max }}, K_{T_{\text {min }}}, K_{E_{\text {max }}}\right) \approx 9.43 \mathrm{Nm}
\end{aligned}
$$

// Nominal motor parameters

$\mathrm{RN}=7.2 ; \mathrm{LN}=0.0177 ; \mathrm{KtN}=1.0 ; \mathrm{KeN}=1.0$;

// Calculating expected deviation in R, L Ke \& Kt $\mathrm{dRN}=0.12^{\star} 7.2 ; \mathrm{dLN}=0.30^{*} \mathrm{LN}$;

$d K t N=K t N^{*} 0.1^{*} \mathrm{KtN} ; \mathrm{dKeN}=\mathrm{KeN}^{*} 0.1^{*} \mathrm{KeN}$;

\section{// Calculating expected Max \& Min in R, L Ke \& Kt $R \max =R N+d R N ; \quad R \min =R N-d R N$; \\ $\mathrm{Lmax}=\mathrm{LN}+\mathrm{dLN}$; \\ $\mathrm{Ktmax}=\mathrm{KtN}+\mathrm{dK} \mathrm{KN}$; \\ Lmin $=\mathrm{LN}-\mathrm{dLN}$ \\ $\mathrm{K}$ tmin $=\mathrm{K} t \mathrm{~N}-\mathrm{dK} \mathrm{tN}$; \\ $\mathrm{Kemin}=\mathrm{KeN}-\mathrm{dKeN}$;}

// Identifying Peak torques for all possible variations for R=[RN Rmax Rmin];

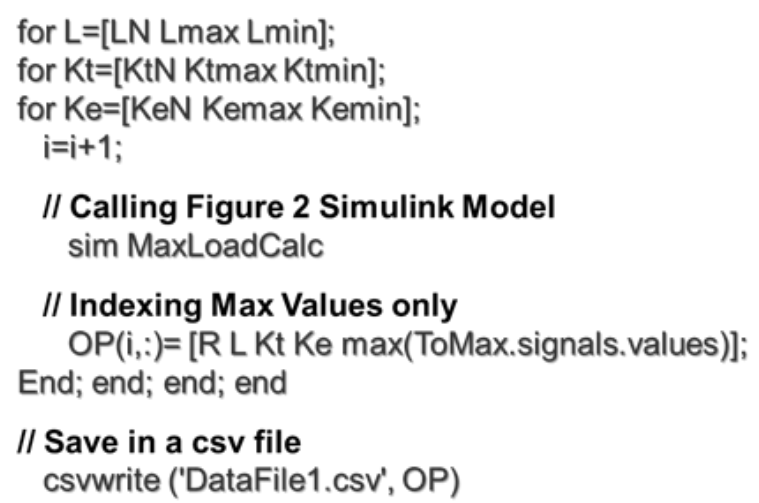

Fig. 7: M-file used to calculate peak torques 


\section{Simulation Tests:}

Simulink simulation models were developed for the two closed loop configurations in Fig. 6. Figures 8 and 9 show the closed loop designs for systems without and with force equalization. The architecture in Fig. 8 includes four independent PI with velocity feedback controllers that are embedded in the controller block, which expands to the subsystem in Fig. 10. In this architecture the controllers reacted to a common reference input and received independent feedback signals (from each motor); and their outputs independently controlled each of the motors, as shown in Fig. 8. Fig. 9 shows the design that considers force equalization. In this case the closed loop includes a single PI with velocity feedback controller that reacted to a common reference input and received average reading values for position and velocity feedback signals; and it outputted a common control signal to simultaneously drive the motors.

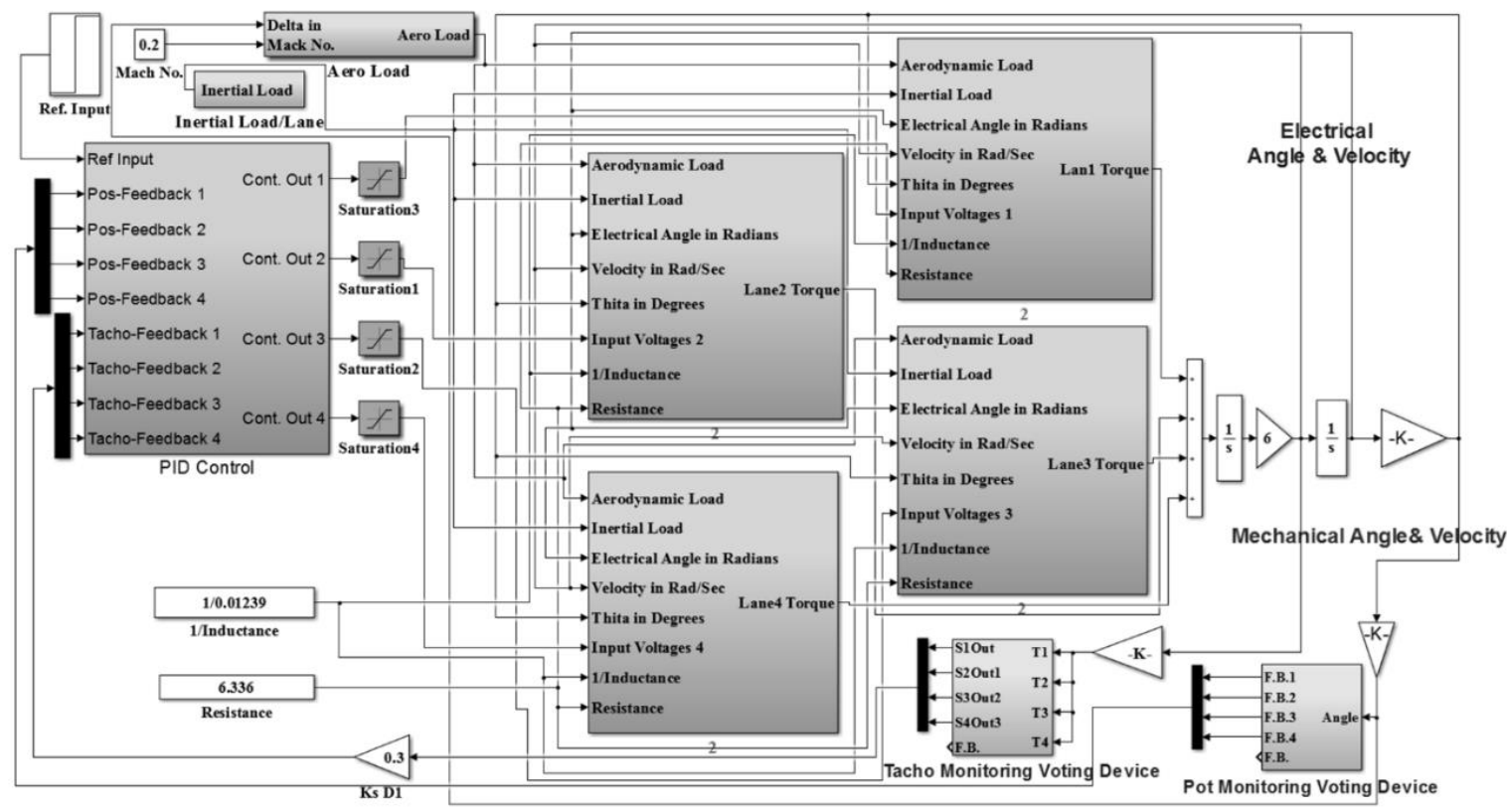

Fig. 8: Closed loop block diagram of the system without force-equalization

In both designs, the top layer included the aerodynamic model and the monitoring and voting devices (MVD) on the feedback sensors. The controller in the architecture with force equalization received average values of the feedback signals. However, the architecture that does not consider force equalization made use of all feedback signals after passing through the 
monitoring devices, as it is clearly shown in Figures 8 and 9, where the feedback signals are multiplexed to the controller.

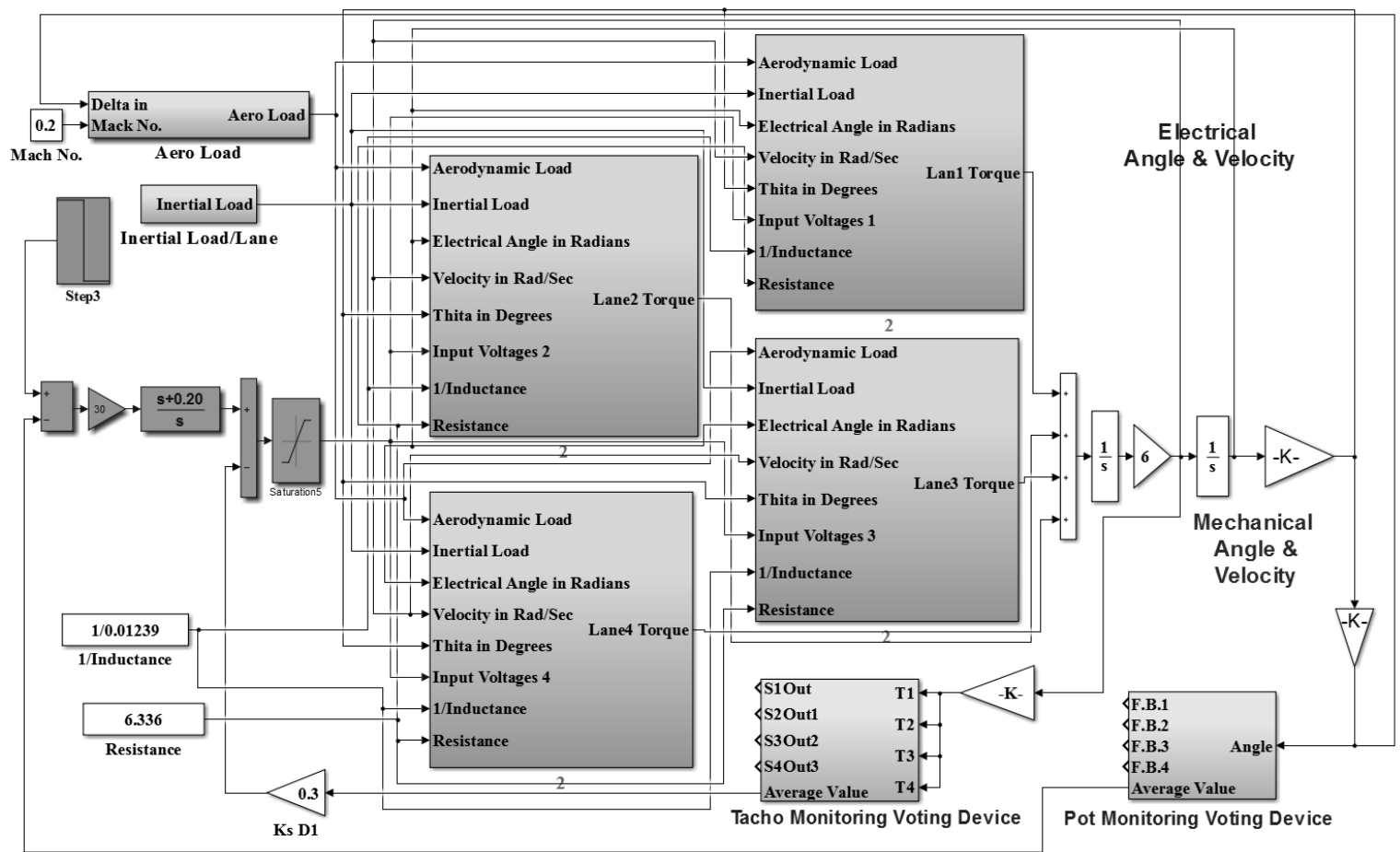

Fig. 9: Closed loop block diagram of the system with force-equalization

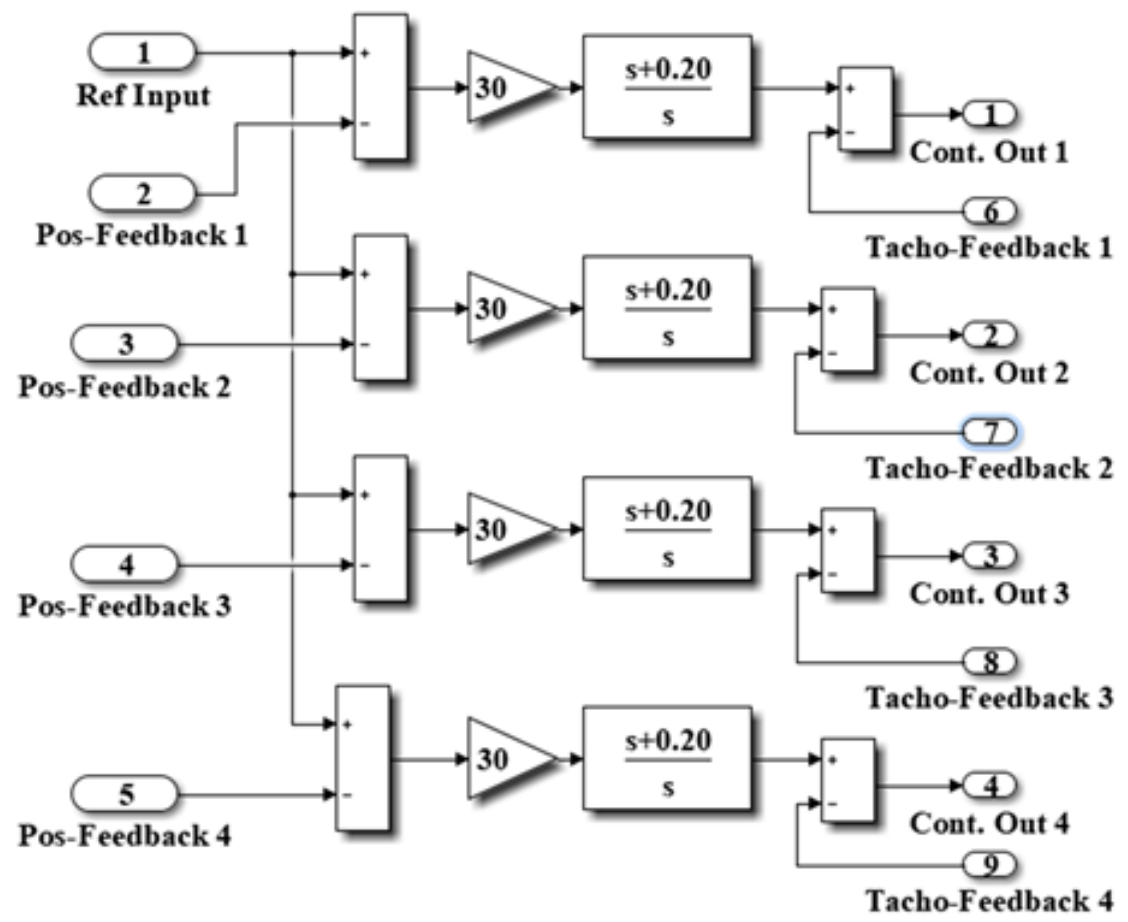

Fig. 10: The controller (PI + velocity feedback) subsystem 


\section{RESUltS AND DiscusSiONS:}

Simulation tests were conducted to evaluate the impact of implementing force equalisation on reducing the possibility of force fight between mismatched lanes, for different flight cases. Motors with nominal and extreme parameters, as well as drift in potentiometer and tachometer readings were also considered. In the analysis, individual and total torques $\left(T_{q_{1 \sim 4}}\right.$ and $\left.T_{T o t a l}\right)$ as well as aileron position control were assessed, however, only results for low aircraft speeds will be presented, as they cater for the worst loading cases.

\subsection{EfFect of FE on ACtuators With Nominal Motor Parameters:}

Figures 11 and 12 show the responses of the individual torques generated by each lane as well as the total output torque, which is basically the algebraic sum of the individual torques. The figures also show the resulting aileron angular deflection response to step inputs of $\pm 9^{\circ}$ and $\pm 18^{\circ}$. The figures clearly demonstrate that similar responses have resulted, with the individual lanes superimposed on each other and add up to make the total torque. Therefore, force equalization had no effect on the system response.

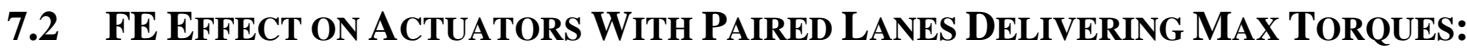

Fig. 13 shows two plots that consider individual and total torques $\left(T_{q_{1 \sim 4}}\right.$ and $\left.T_{\text {Total }}\right)$, as well as the aileron deflection responses to $18^{\circ}$ step input during low-aircraft-speed $(\mathrm{M}=0.2)$. Fig. 13a presents test results to an architecture that does not utilize FE, and Fig. 13b presents test results to an architecture that utilizes FE. Both plots assume that motor parameters are set to their extreme tolerances, so that: one pair $\left(\right.$ Lanes $\left._{1 \& 2}\right)$ include motors with parameters that will enable the pair to deliver the higher band of peak torques, equation (23). The other pair Lanes $_{3 \& 4}$ were assumed to include motors with parameters that enable the lanes to deliver the lower band of peak torques, equation (24). Both plots assume zero drift in transducers readings. The figures clearly demonstrate the resulting inherent deviation in the torques delivered 
by $T_{q_{1 \& 2}}$ and $T_{q_{3 \& 4}}$. It is also clear that in both techniques deviations between the lanes is rapidly reduced, and that the actuator position settles at $\delta_{a}=18.4^{\circ}$.

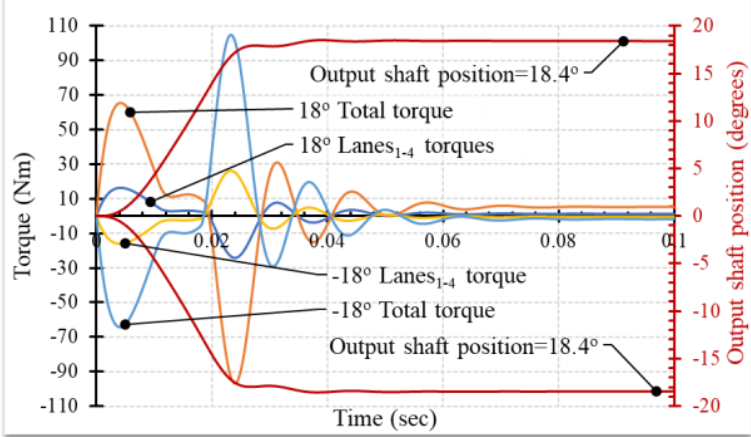

(a) $\pm 18^{\circ}$

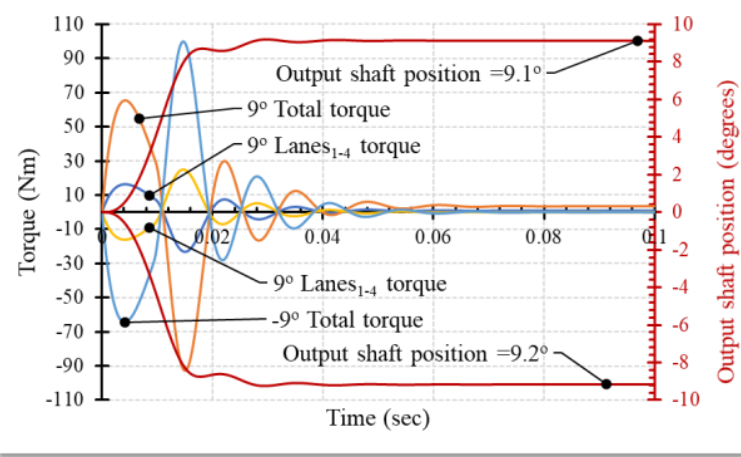

(b) $\pm 9^{\circ}$

Fig. 11: Individual and total torques as well as aileron deflection (with force equalization) for an actuator with motors with nominal parameter.

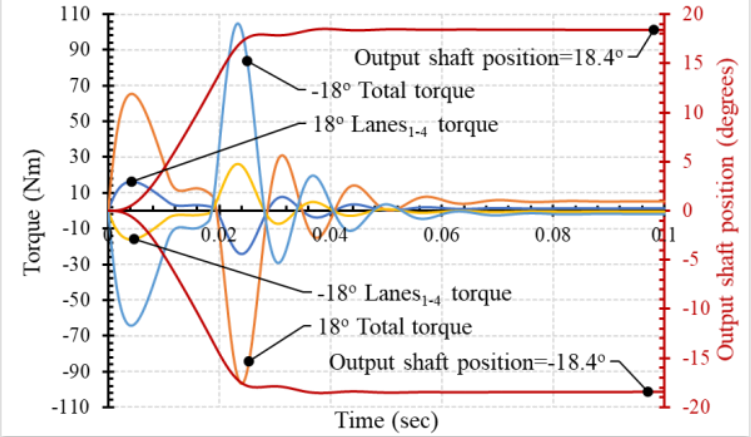

(a) $\pm 18^{\circ}$

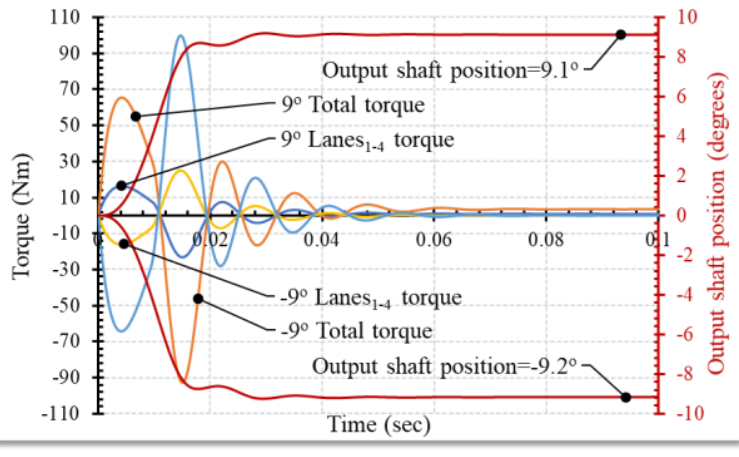

(b) $\pm 9^{\circ}$

Fig. 12: Individual and total torques as well as aileron deflection (without force equalization) for an actuator with motors with nominal parameter

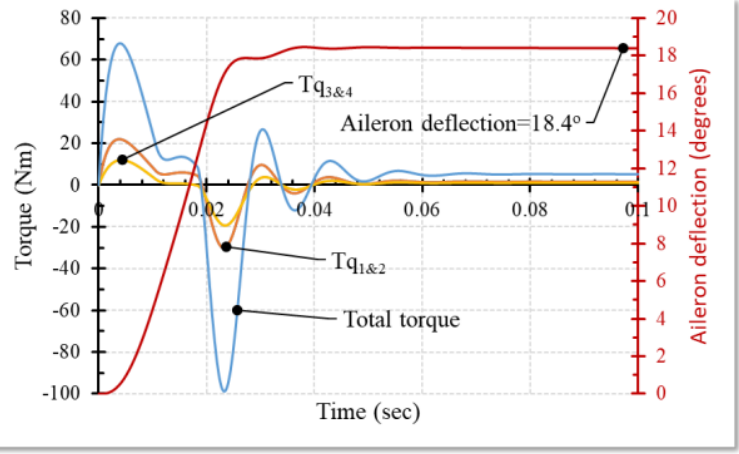

(a) Without Force-Equalization

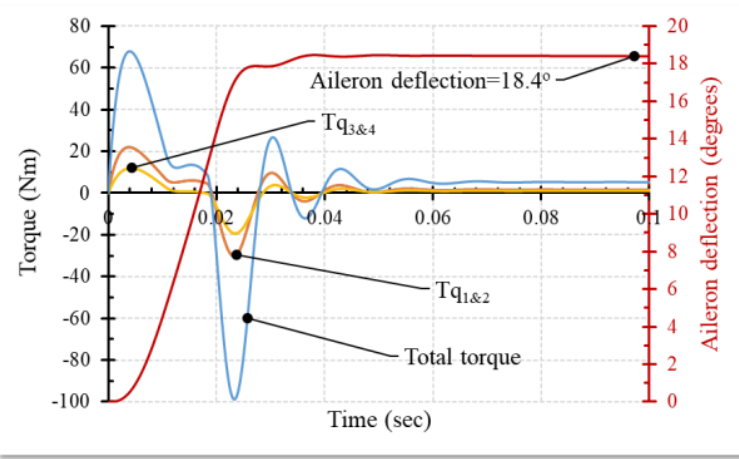

(b) With Force Equalizations

Fig. 13: Actuator response due to inherent deviations in motor parameters, with Lanes ${ }_{1 \& 2}$ and Lanes ${ }_{3 \& 4}$ delivering \pm maximum torques, and no drift on any of the Tachometers 


\subsection{Fe Effect on Actuators With Paired Lanes Delivering Max Torques and HAVE DRIFT IN TACHOMETER READINGS:}

Figures 14 and 15 show two columns of plots that consider individual and total torques $\left(T_{q_{1 \sim 4}}\right.$ and $\left.T_{\text {Total }}\right)$, as well as the aileron deflection responses to $18^{\circ}$ step input during lowaircraft-speed $(M=0.2)$. The plots in the left column present test results to an architecture that does not utilize FE, however, the plots in the right column present test results to an architecture that utilizes FE. All tests, assume that motor parameters are set to their extreme tolerances, so that: one pair $\left(\right.$ Lanes $\left._{1 \& 2}\right)$ include motors with parameters that will enable the pair to deliver the higher band of peak torques, equation (23). The other pair Lanes $_{3 \& 4}$ were assumed to include motors with parameters that enable the lanes to deliver the lower band of peak torques, equation (24). The tests consider $0 \%, 1 \%, 10 \%, 50 \%$ and $100 \%$ drift in tachometer readings. Although it is highly likely that the tachometers will have tolerances in the region of $1 \%$, higher order deviations were considered for the following reasons to: 1) easily examine and visualise the effect of force equalisation (or its absence); and 2) understand the effect of such scenarios on the system, when failures do occur and go undetected.

The plots in Fig. 14a consider the case when the tachometer on Lane $_{1}$ experiences $1 \%, 10 \%$, $50 \%$, and $100 \%$ drift in its measurement. The figures clearly show that when force equalization is not considered (graphs on the left-hand side) higher drifts in tachometer readings resulted in larger variation on the torque. However, when force equalization is considered (graphs on the right-hand side) the variation in $T q_{1}$ is more limited. This is expected as force equalization utilises the averaged of the fed back signals. Close examination of the results also reveals how $L_{2 a n}$ reacts in response to the increase in torque produced by $L a n e_{1}$ due to $0 \sim 100 \%$ drift in the tachometer reading. For example, at $\mathrm{t}=0.024 \mathrm{sec}$, the torque in Lane $_{1}$ increments from $30 \mathrm{Nm}$ (no drift in tachometer reading, Fig. 13a) to $43 \mathrm{Nm}$ (due to $100 \%$ drift in tachometer 
reading, Fig. 14a). This increase is matched by drop in the torques delivered by Lane $_{3}$ for 20Nm (Fig. 13a) to 4Nm (Fig. 14a). However, when FE was utilized, it is clear that there was hardly any torque compensation needed from Lane $_{3}$.
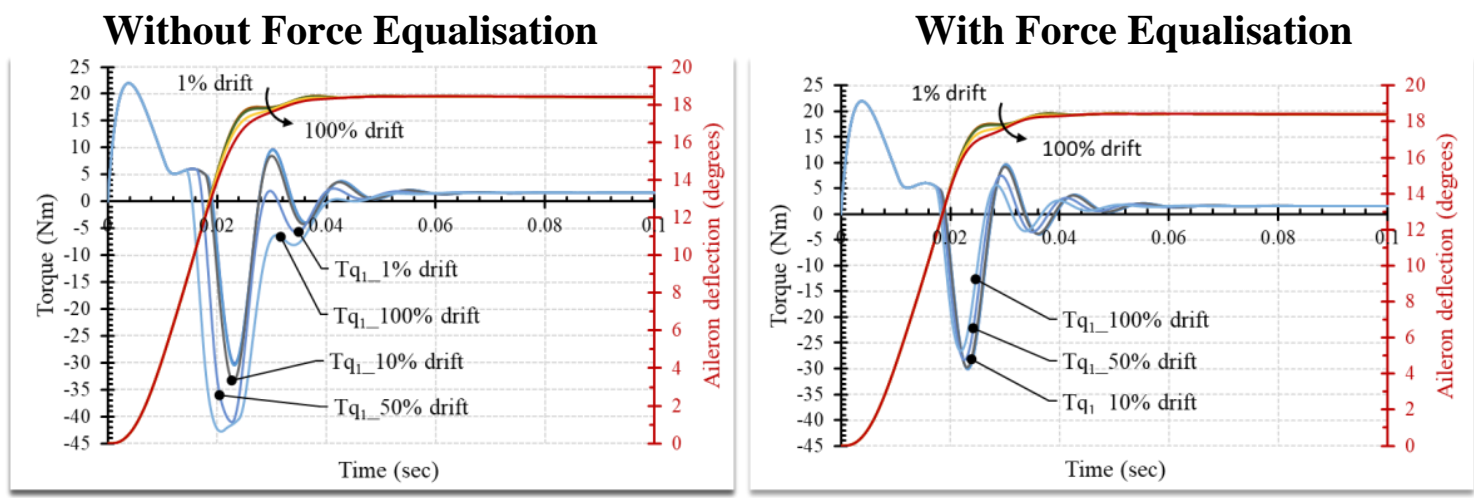

(a) Developed torque on lane $_{1}$ due to $1 \sim 100 \%$ drift in tachometers readings on lane $e_{1}$
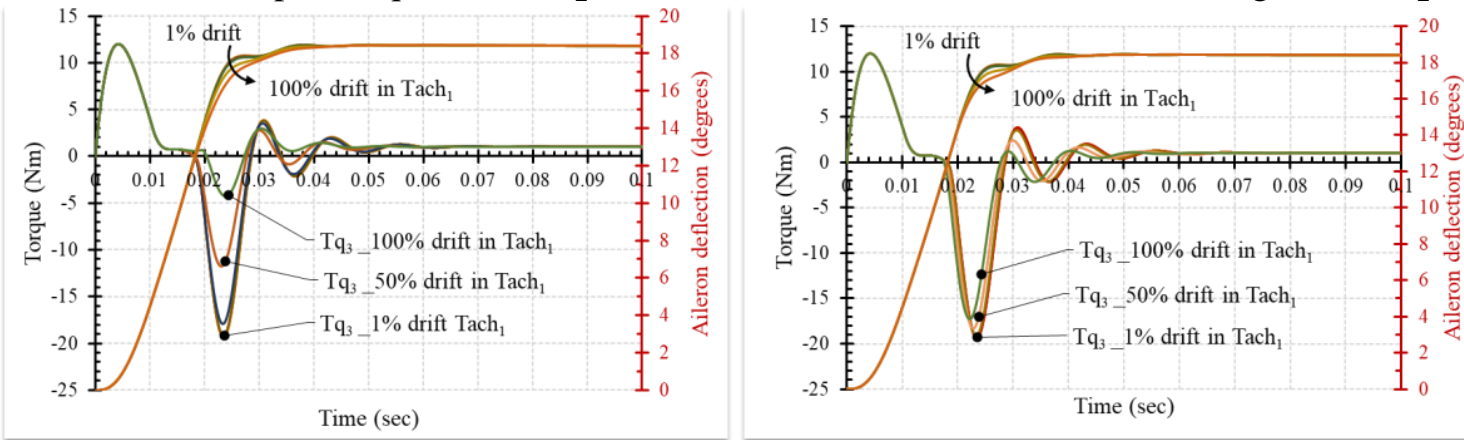

(b) Developed torque on lane $_{3}$ due to $1 \sim 100 \%$ drift in tachometers readings on lane $e_{1}$
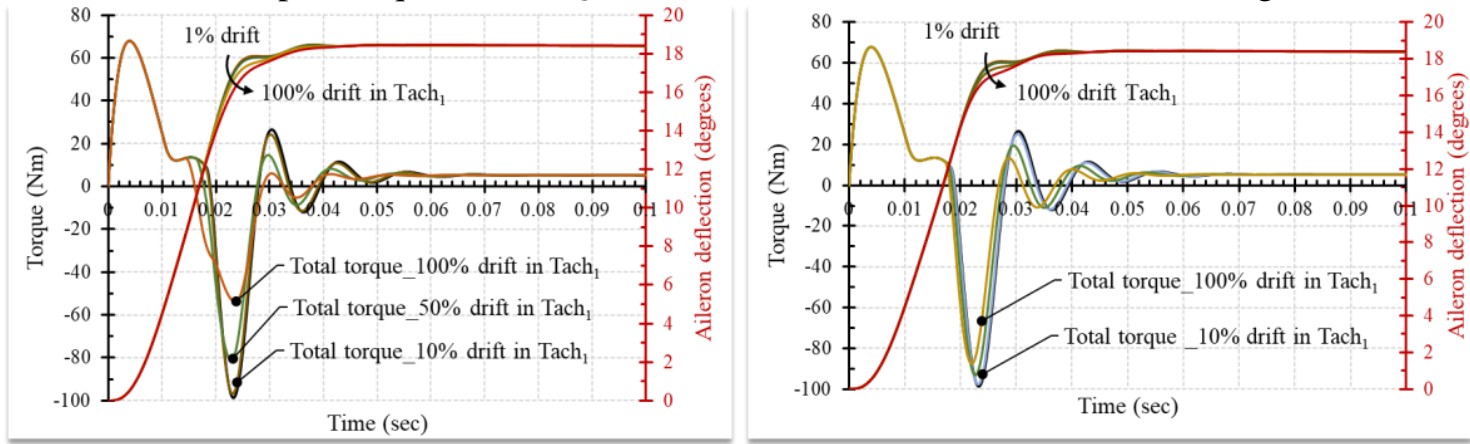

(c) Total developed torque due to $1 \sim 100 \%$ drift in tachometers readings on lane $_{1}$

Fig. 14: Actuator response due to inherent deviations in motor parameters (with Lanes $1 \& 2$ and Lanes $_{3 \& 4}$ delivering \pm maximum torques); and drift in tachometer readings

Fig. $14 \mathrm{c}$ shows the resulting $T_{\text {Total }}$ to such variation in the presence and absence of equalisations, where when FE was utilised, a much similar trend has resulted to that of the nominal $(0 \sim 1 \%)$ drift in tachometer readings. The figures clearly show that the actuator response in both cases is very much unaffected. 
The plots in Fig. 15 show individual and total torques due to drift in the tachometers' readings on two lanes, Lane $_{2 \& 4}$. Here, only the $50 \%$ drift in the tachometer readings cases are presented. Clearly a similar argument to the one mentioned above is true, where a similar and regular trend is achieved if force equalization is adopted, as shown in Figures 15a and 15b. Fig. 15d shows the response of Lanes $_{2 \& 4}$ due to drift on the tachometer readings on Lanes $_{1 \& 3}$, where, Lanes $_{1 \& 2}$ have the same motor parameters, and Lanes ${ }_{3 \& 4}$ have the same parameters. Despite the fact that motor pairs share the same parameters, drift in tachometers on one of the lanes in a pair will result in further torque deviations, which was possible to eliminate when $\mathrm{FE}$ is adopted. Moreover, peak disparities between the two sets of pairs in Fig. 15d were clearly reduced between Lanes $_{1 \& 2}$ and Lanes $_{3 \& 4}$, which is reflected by the overall increase in the total output torque, as shown in Fig. 15c.

\subsection{Fe Effect on ACtuators With Paired Lanes Delivering MaX Torques and HaVe Drift in Potentiometer Readings:}

The plots in Figures 16 and 17 examine the effect of drift in potentiometer readings on the

individual $\left(T_{q_{1 \sim 4}}\right)$ and total $\left(T_{\text {Total }}\right)$ torques. The figures also examine the aileron angular deflection response to $18^{\circ}$ reference inputs during low-aircraft-speed. Just as in the previous section, the tests (in both figures) assumed that motor parameters are set to their extreme tolerances, so that Lanes $_{1 \& 2}$ and Lanes $_{3 \& 4}$ delivered peak torques at the higher $15.53 \mathrm{Nm}$ and lower $9.43 \mathrm{Nm}$ bands respectively. Fig. 16 shows simulation results from an architecture that does not utilize FE. These are compared to the results in Fig. 17 where FE was considered. The tests considered drifts of $0 \%, 1 \%, 10 \%, 50 \%$ and $100 \%$ in potentiometer readings. Again, although it is highly likely that potentiometers are expected to experience drift in the region of $1 \%$, higher orders were considered to: 1) easily examine and visualise the effect of FE; and 2) understand the effect of drift in potentiometer reading on the system, when a developed failure goes undetected. 
Without Force Equalization

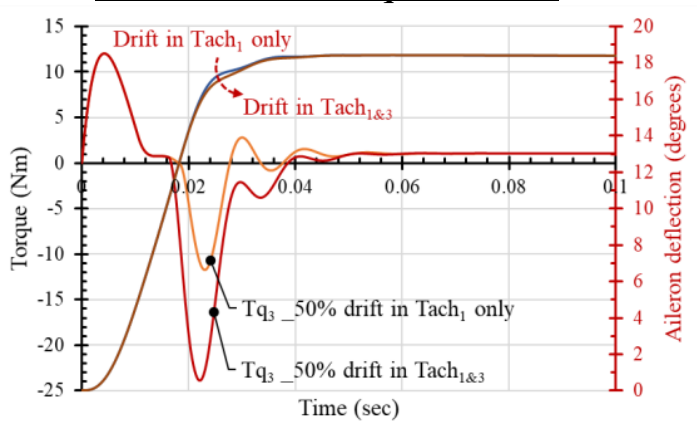

$\underline{\text { With Force Equalization }}$

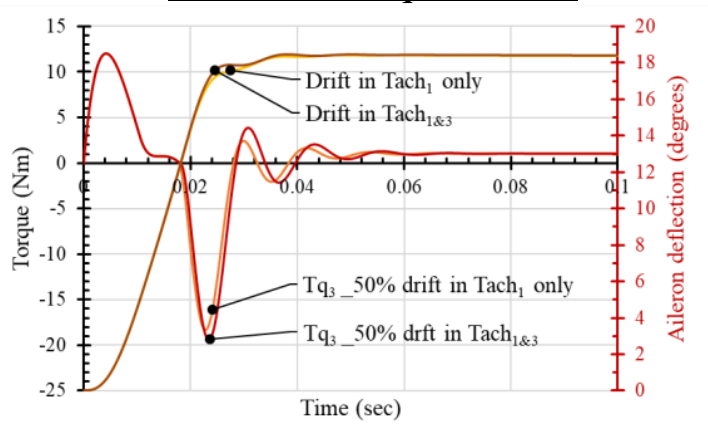

(a) Developed torque on Lane $_{3}$ due to $50 \%$ drift in tachometer readings on Lane $_{1} \&$ Lane $_{1 \& 3}$
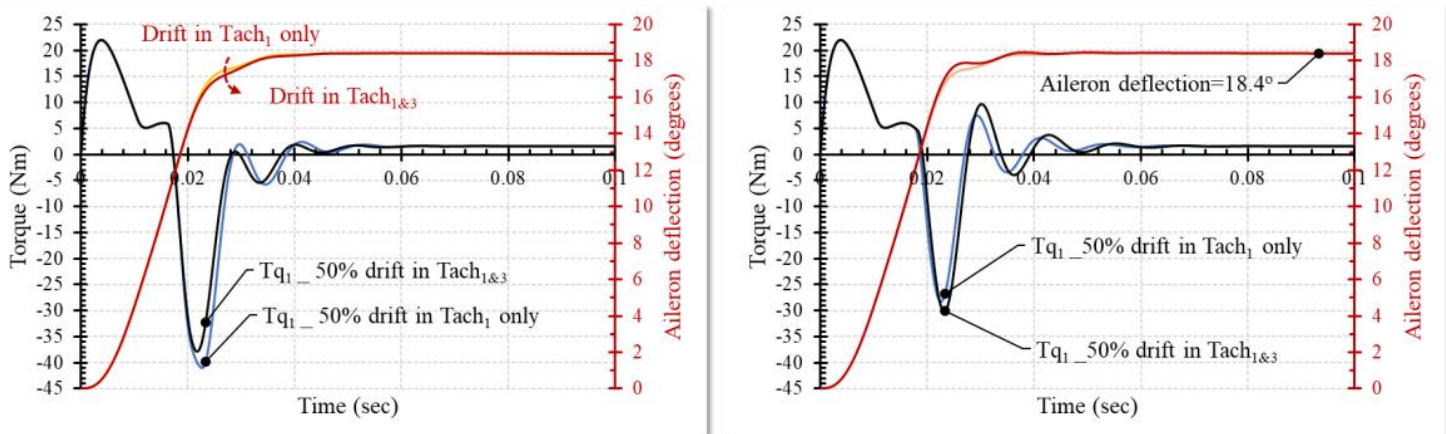

(b) Developed torque on Lane $_{1}$ due to $50 \%$ drift in tachometer readings on Lane $_{1} \&$ Lane $_{1 \& 3}$
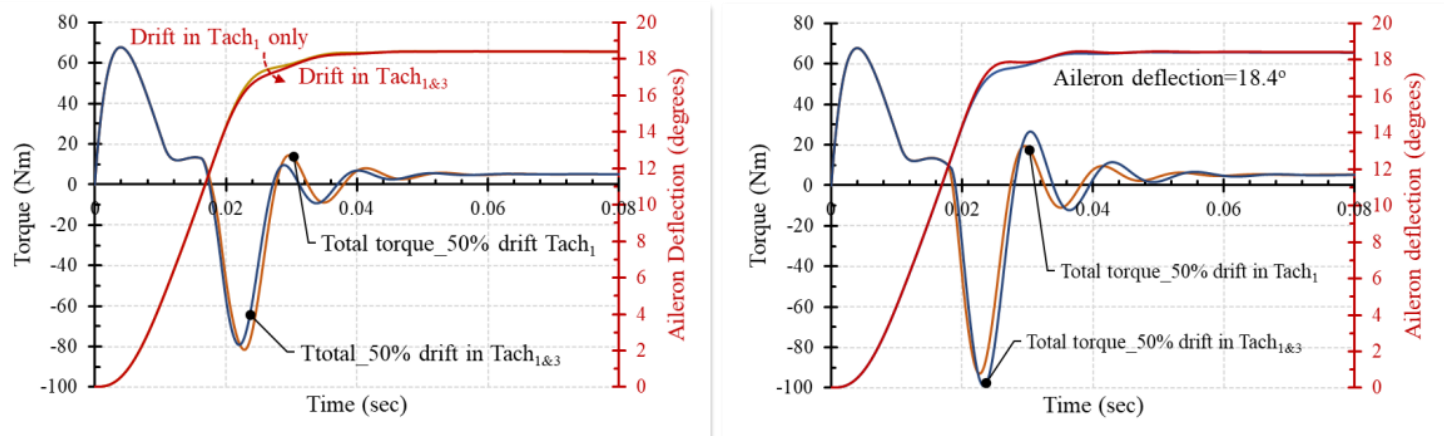

(c) Total developed torque due to $50 \%$ drift in tachometer readings on Lane $_{1} \&$ Lane $_{1 \& 3}$
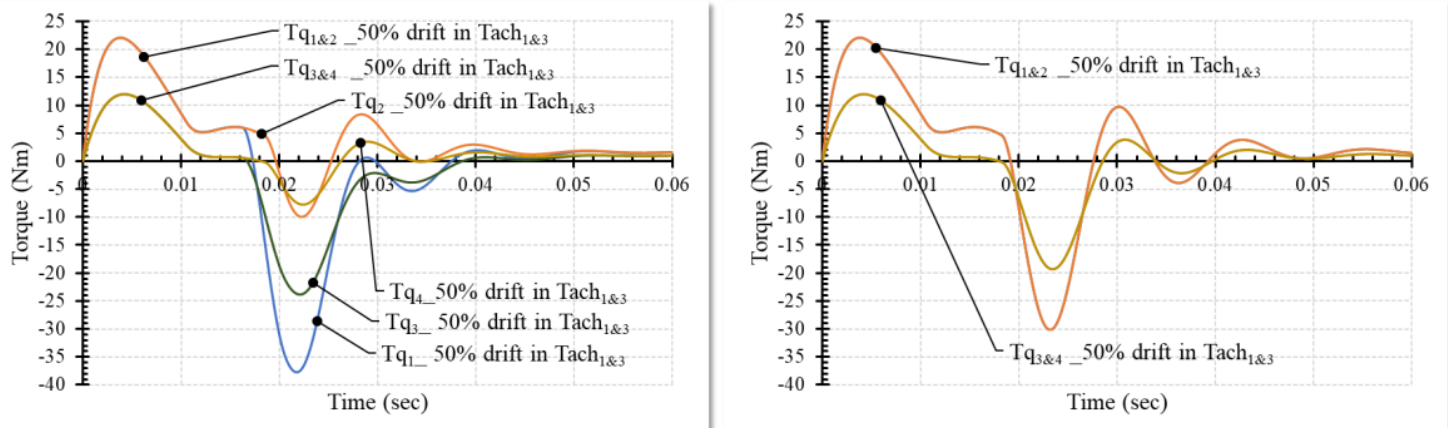

(d) Developed torques on Lane $_{1 \sim 4}$ due to $50 \%$ drift in tachometer readings on Lane $_{1 \& 3}$

Fig.15: Actuator response to drift in two tachometers $\left(\right.$ Tach $\left._{1}\right)$ and $\left(\right.$ Tach $\left._{3}\right)$ with and without lane equalization.

(Motors in the actuators have parameters with tolerances set so that \pm maximum torque deliver per pair is possible) 
Fig. 16a shows inherent transient deviations in the torques delivered by $T_{q_{1 \& 2}} \& T_{q_{3 \& 4}}$, (without the influence of any drift in potentiometer reading). Such deviations rapidly merge to equal and steady values of $1.3 \mathrm{Nm}$ resulting in a total torque of $5.2 \mathrm{Nm}$. This figure also shows that the actuator response meets the reference input demand and settles at $18.4^{\circ}$. Fig. $16 \mathrm{~b}$ shows the results for a $10 \%$ drift in the reading of the potentiometer on Lane $_{1} 1$ (i.e. Potentiometer ${ }_{1}$ ). The figure, clearly show drop in the readings on the other pots, indicating that the other lanes slow down so that the common output shaft angular displacement meets that demanded by the reference input. The drift in potentiometer reading has resulted in a drop in the delivered torque by $L_{\text {ane }}$ (i.e. $T q_{1}$ ). The drop in $T q_{1}$ is compensated by an increase in the torque contribution by the other lanes. Similar results are achieved in Fig. $16 \mathrm{c}$ when the reading on Pot $_{1}$ undergoes a drift of $50 \%$, where: 1) the remaining lanes slow down so that the input command of $18^{\circ}$ is nearly achieved $\left.\left(17.8^{\circ}\right) ; 2\right)$ the drop in $T q_{1}$, is matched by an increase in the output torque in the remaining lanes $T q_{2 \sim 4}$.

Figures $16 \mathrm{~d}$ and $16 \mathrm{e}$ show the developed torques, the pots readings and the actuator's common output position response to a $50 \%$ drift in each of Pots $_{1 \& 3}$ readings. This resulted in an increase in angular position in Lanes $_{2 \& 3}$ and a drop in $T q_{1 \& 3}$, which is matched by the increase in torques in $T q_{2 \& 4}$ to deliver a resultant output torque $T_{\text {Total }}$. Clearly, an architecture that does not implement FE is ineffective in reducing or eliminating force fight between mismatched lanes. The results in Fig. 16e demonstrate a clear increase in force fight between the mismatched lanes, if the drift in the pots is not detected and isolated immediately. Therefore, FE is crucial in eliminating force fight, as demonstrated in Fig. 17 and will be explained next.

Fig. 17a shows tests for $0 \%$ drift on any of the potentiometers (similar to Fig. 16a); Fig. 17b shows tests for $50 \%$ drift on the potentiometer reading in lane $_{1}$; Fig. $17 \mathrm{c}$ shows tests for $50 \%$ 
drifts on the reading of $\mathrm{Pot}_{3}$ only; and Fig. $17 \mathrm{~d}$ shows tests for $50 \%$ drifts on the readings of Pots $_{1 \& 3}$. The figures clearly show the effectiveness of $\mathrm{FE}$ in eliminating toque disparities between lanes, despite the high drift in potentiometer readings. Moreover, the figures clearly show the elimination of torque deviations between lanes with healthy potentiometers and lanes with potentiometers that suffered $50 \%$ drift in their readings. Thus, an architecture with FE offers a better solution in eliminating force-fight between mismatched lanes, when drift in potentiometer readings goes undetected.

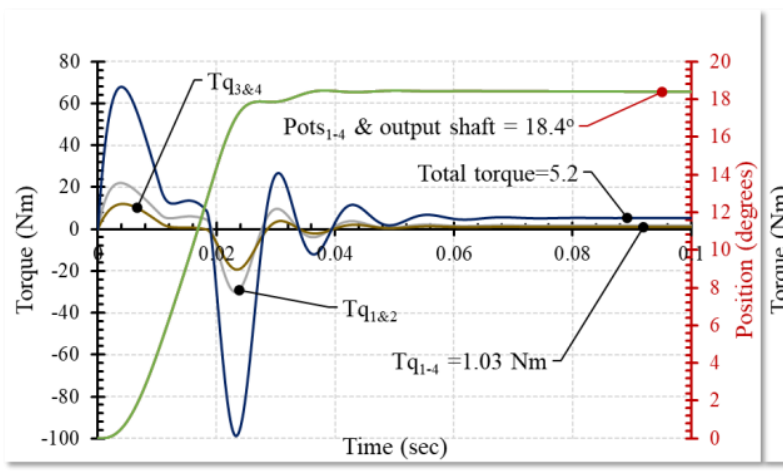

a) $0 \%$ drift in Pot $_{1 \sim 4}$

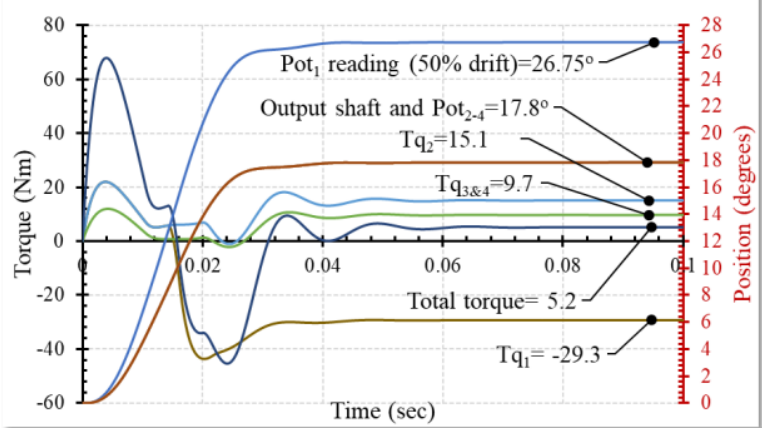

c) $50 \%$ drift in Pot $_{1}$

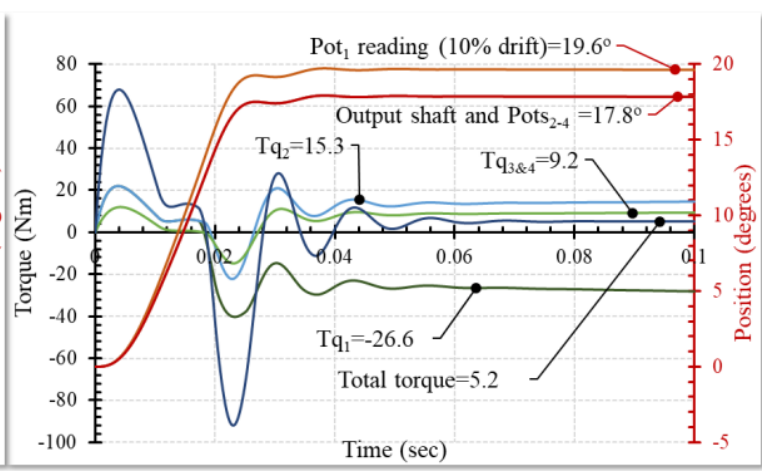

b) $10 \%$ drift in Pot $_{1}$

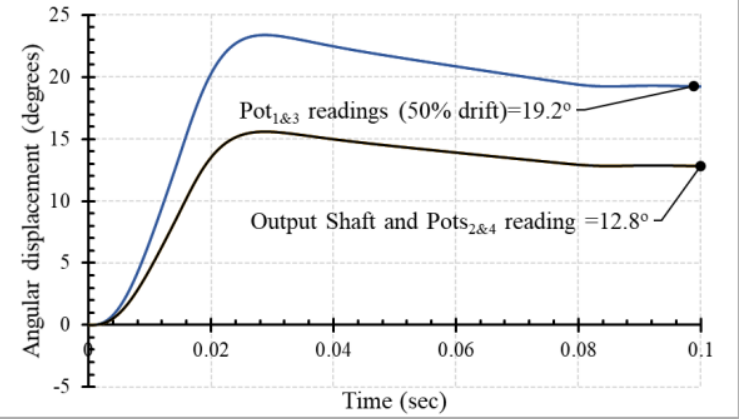

d) $50 \%$ drift in $\operatorname{Pot}_{1 \& 3}$

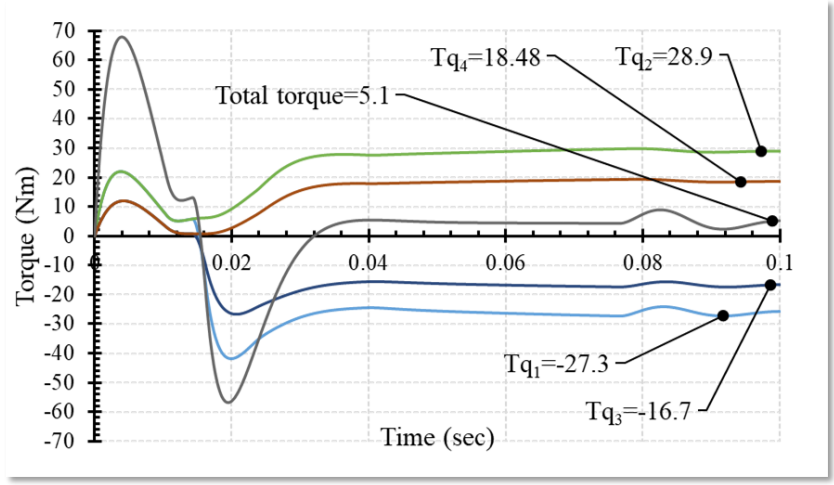

e) $50 \%$ drift in $\operatorname{Pot}_{1 \& 3}$

Fig. 16: Actuator response to drift in potentiometers $\left(\mathrm{Pot}_{1-4}\right)$ [ \pm Max parameter deviation and _without force equalization] 


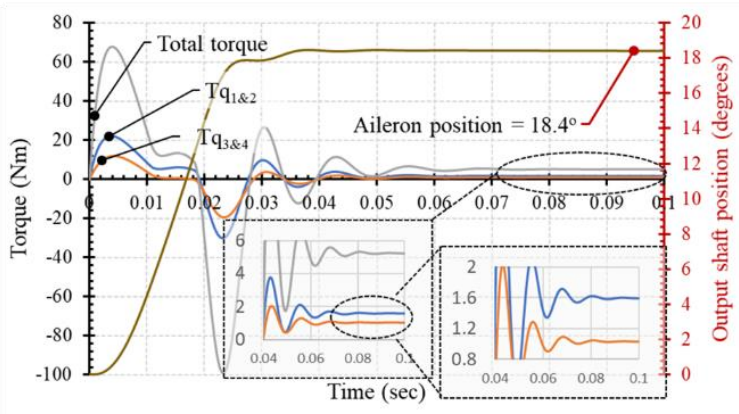

a) $0 \%$ drift in Pots $1 \sim 4$

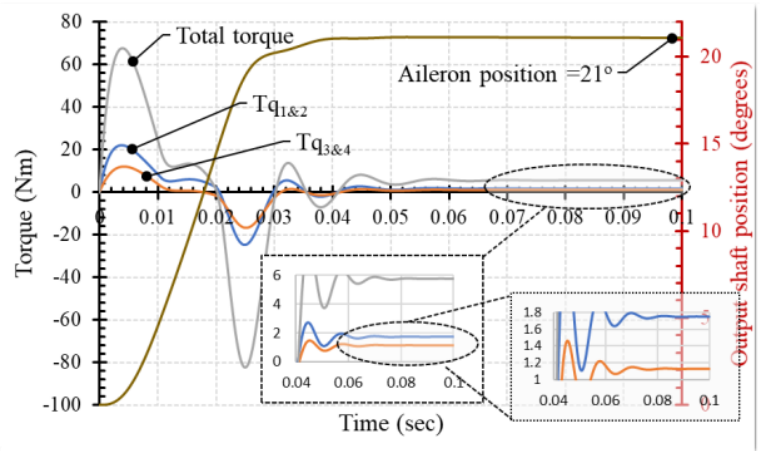

c) $50 \%$ drift in $\mathrm{Pot}_{3}$ only

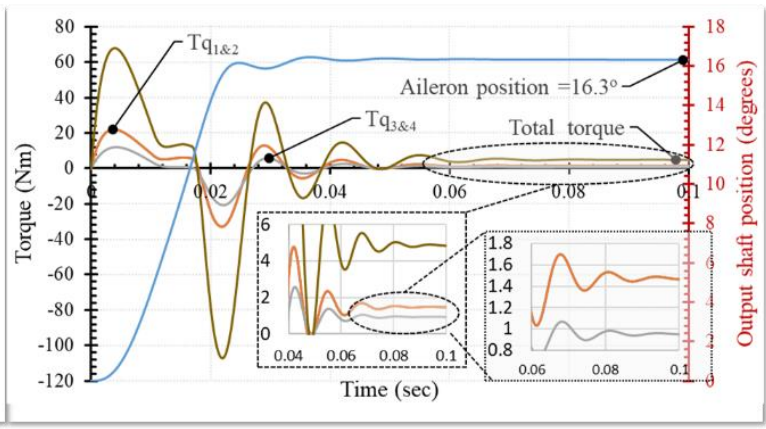

b) $50 \%$ drift in Pot $_{1}$ only

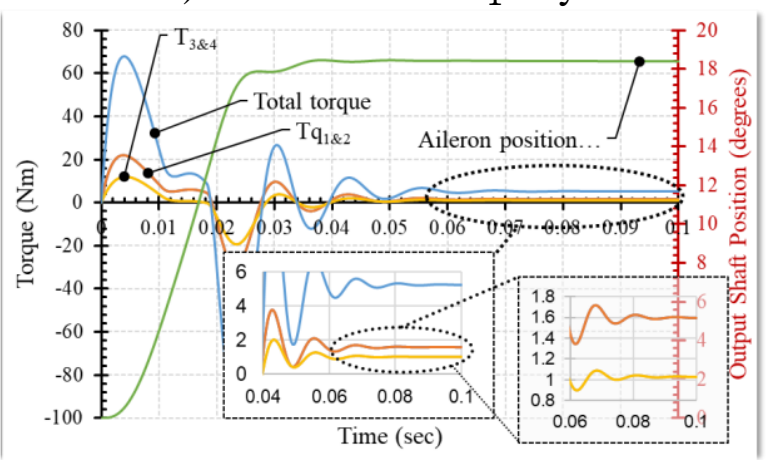

d) $50 \%$ drift in Pots $1 \& 3$

Fig. 17: Individual and total torque and actuator response to drift in potentiometers readings $\left(\right.$ Pot $\left._{1-4}\right)$

[ \pm Max parameter deviation and_with force equalization]

\section{Conclusion:}

The paper addressed the possibility of force fight in a torque-summed architecture with mismatched lanes. In the study, a 4-lanes actuation system (that is capable of driving the aerodynamic and inertial loads similar to those acting on the inner board aileron control surface of the Sea Harrier) was considered, and the actuator was designed so that it is capable of driving the loads following two motor failures. The effectiveness of lanes equalization in architectures that utilised PI with velocity feedback to position control the common output shaft. In the study, architectures that utilised force equalizations employed one common controller that reacted to averaged feedback signals and outputted one common control signal to drive the system's motors. However, architectures that did not utilise force equalisation included independent controllers for each of the lanes, where, each controller received independent feedback signals 
and outputted independent control signals to each of the motors. The analysis clearly revealed that force equalisation was most effective in reducing torque disparities due to drift in one or more of the potentiometer or tachometer readings. However, it was proven that force equalisation was ineffective in reducing torque disparities due to inherent deviations in motor parameters. Therefore, alternative hardware compensating techniques might be necessary.

\section{References:}

[1] K. A. Hair, "Electromechanical actuation reliability and survivability, NAECON," in NAECON, 1983.

[2] D. Ward, "The all electric helicopter," in NAECON, 1983.

[3] R. Whitaker, A. Harmon and L. Haynes, "A survivable fly-by-wire spoiler actuation system featuring non-flammable fluid, 8000 psi hydraulics and direct drive valves," in NAECON, 1985.

[4] F. Annaz, "Fundamental design concepts in multi-lane smart electromechanical Actuators," Smart Materials and Structures, Smart Mater. Struct., vol. 14, pp. 1227-1238, 2005.

[5] J. B. Leonard, “A system look at the electromechanical actuation for primary flight control," in NAECON, 1983.

[6] K. Thompson, "Notes on the electric control of large aeroplanes," NAECON, p. 595, 1987.

[7] K. Thompson, R. Alden R and L. Hunter, "Lockheed-Georgia and electric primary flight control systems," NAECON, p. 588, 1985.

[8] K. Thompson, K. Eitenmiller and L. Hunter, "Demonstration for electromechanical actuation technology for military air cargo transport," NAECON, p. 87, 1983.

[9] G. Bradbury, "Development of an advanced primary flight control electromechanical actuator," NAECON, p. 602, 1987.

[10] A. Ralph , “C-141 and C-130 Power-By-Wire Flight Control Systems,” NAECON 91, vol. 2, p. 5339, May 20-24, 1991.

[11] C. J. Smith, "Electric actuation system duty cycle,” NAECON 91, vol. 2, pp. 540-545, May 20-24.

[12] S. C. Jensen, G. D. Jenney and D. Dawson, "Flight test experience with an electromechanical actuator on the F-18 Systems Research Aircraft," in Digital Avionics Systems Conference, 2000.

[13] C. Pond and C. Wyllie, "Test results of a unique high power electric motor,” IEEE, 1983.

[14] R. Davidson, "Flight Control Design and Test of the Joint Unmanned Combat Air System (J-UCAS) X45A," in AIAA 3rd "Unmanned Unlimited" Technical Conference, 2004.

[15] C. Cossar, L. Kelly, C. Whitley, C. Maxwell and D. Moorhouse, "The Design of a Switched Reluctance Drive for Aircraft Flight Control Surface Actuation," in IEE Colloquium on Electrical Machines and Systems for the More Electric Aircraft, 1999.

[16] K. Atallah, F. Caparrelli, C. Bingham, N. Schofield, D. Howe, P. Mellor, C. Maxwell, D. Moorhouse and C. Whitley, "Permanent magnet brushless drives for aircraft flight control surface actuation," in IEEE Colloquium on Electrical Machines and Systems for the More Electric Aircraft, 1999.

[17] M. Aten, C. Whitley, G. Towers, P. Wheeler, J. Clare and K. Bradle, "Dynamic performance of a matrix converter driven electro-mechanical actuator for an aircraft rudder," in 2nd International Conference on Power Electronics, Machines and Drives, 2004.

[18] J. Bennett, B. Mecrow, A. Jack and D. Atkinson, “A Prototype Electrical Actuator for Aircraft Flaps," IEEE TRANSACTIONS ON INDUSTRY APPLICATIONS, vol. 46, no. 3, pp. 915-921, MAY/JUNE 2010.

[19] J. Bennett, Fault Tolerant Electromechanical Actuators for Aircraft, Newcastle: Newcastle University, 2010. 
[20] M. Rottach, C. C. Gerada, T. Hamiti and P. Wheeler, "Fault-tolerant electrical machine design within a Rotorcraft Actuation Drive System optimization," in 6th IET International Conference on Power Electronics, Machines and Drive, 2012.

[21] B. Ganesh, R. Jhanwar, M. Kodeeswaran and P. Kumar, "Design of 25kW Redundant Linear ElectroMechanical Actuator for Thrust Vector Control Applications. IIT Roorkee, India, 2013, pp. 1033-1039," in Proceedings of the 1st International and 16th National Conference on Machines and Mechanisms (iNaCoMM2013), IIT Roorkee, India, 18-20 Dec 2013.

[22] B. Biju Prasad, R. Sandeep, R. Aravind, P. Kumar and U. Naik, “Optimum Design of a Fault Tolerant Linear Electromechanical Actuator for the Lower Stage Thrust Vector Control of a Satellite Launch Vehicle," in 14th European Space Mechanisms \& Tribology Symposium, Constance, 28-30 September 2011.

[23] A. Nosov, "Power electromechanical drive based on planetary roller-screw gear of improved accuracy," MACHINE-BUILDING ENGINEERING AND MACHINE SCIENCE, vol. 22, no. 4, p. 4, 2015.

[24] Technodinamika, "Technodinamika is developing the first electromechanical landing gear retraction and extension system in Russia," Technodinamika, 22 December 2015.

[25] Technodinamika, "Technodinamika to provide MS-21 with electromechanical reverser actuators," Technodinamika, 21 March 2016.

[26] C. Lupo, B. Robertson and G. Gafka, "The X-38 V-201 Fin Fold Actuation Mechanism," in 37th Aerospace Mechanisms Symposium, 2004.

[27] J. Hagen, L. Moore, J. Estes and C. Layer, “The X-38 V-201 Flap Actuator Mechanism,” in 37th Aerospace Mechanisms Symposium, 2004.

[28] M. Schwabacher, J. Samuels and L. Brownston, "NASA integrated vehicle health management technology experiment for X-37," in SPIE 4733, Component and Systems Diagnostics, Prognostics, and Health Management I, 16 July 2002.

[29] S. Jensen, "Electro-Mechanical Actuator (EMA) Validation Program,” 1998.

[30] Y. Lin, E. Baumann, D. Bose, R. Beck and G. Jenney, "Tests and Techniques for Characterizing and Modeling X-43A Electromechanical Actuators,” NASA Dryden Flight Research Center;, Edwards, CA, United States, 01 Dec 2008.

[31] J. R. Hoffman, "Passive Load Testing for evaluation of Electromechanical Actuators," Air Force Institute of Technology, March, 2018.

[32] L. Wang, "Force Equalization for Active/Active Redundant Actuation System Involving Servo-hydraulic and Electromechanical Technologies," Université de Toulouse; Institut National des Sciences Appliq, Toulouse, December 2012.

[33] F. Annaz, "Worthy Test Programs and Developments in Smart Electromechanical Actuators," Smart Materials and Structures, vol. 16, 2007.

[34] F. Annaz, Design and Development of Multi-Lane Smart Electromechanical Actuators, IET, 2014.

[35] Mil-F-83300, Flying qualities of piloted VSTOL aircraft, 1970.

[36] 1. Mil-C, Flying qualities of piloted VSTOL aircraft, 1970.

[37] Mitchell and A. Gauthier, Advanced Continuous Simulation Language Reference Manual) Paperback, Mitchell \&Gauthier, 1995.

[38] I. M. D. Publication, "Kollmorgen SILVERLINETM Brushless Series Motors," Kollmorgen Motion Technologies Group, 1989. [Online]. Available: https://www.kollmorgen.com/sites/default/files/public_downloads/Silverline\%20Motor\%20Catalog.pdf. [Accessed 06 January 2020].

[39] M. Inc., "Rotary Variable Differential Transformer (RVDT,” 2019. [Online]. Available: https://www.moog.com/literature/MCG/RVDTDtS.pdf. [Accessed 06 January 2020].

[40] M. I. a. Research, "Rotary Variable Differential Transducer," 2019. [Online]. Available: https://www.mtcind.com/mtc-rvdt-116. [Accessed 06 January 2020]. 